\title{
Review
}

\section{DNA Hydroxymethylation in Smoking-Associated Cancers}

\author{
Ahmad Besaratinia*(D), Amanda Caceres and Stella Tommasi (D) \\ Department of Population \& Public Health Sciences, USC Keck School of Medicine, University of Southern \\ California, M/C 9603, Los Angeles, CA 90033, USA; Amanda.Caceres@med.usc.edu (A.C.); \\ tommasi@med.usc.edu (S.T.) \\ * Correspondence: besarati@med.usc.edu; Tel.: +1-(323)-442-0088; Fax: +1-(323)-865-0103
}

check for updates

Citation: Besaratinia, A.; Caceres, A.; Tommasi, S. DNA

Hydroxymethylation in Smoking-

Associated Cancers. Int. J. Mol. Sci. 2022, 23, 2657. https://doi.org/ $10.3390 /$ ijms 23052657

Academic Editor: Agustin F. Fernandez

Received: 10 February 2022 Accepted: 27 February 2022 Published: 28 February 2022

Publisher's Note: MDPI stays neutral with regard to jurisdictional claims in published maps and institutional affiliations.

Copyright: (C) 2022 by the authors. Licensee MDPI, Basel, Switzerland. This article is an open access article distributed under the terms and conditions of the Creative Commons Attribution (CC BY) license (https:// creativecommons.org/licenses/by/ $4.0 /)$.

\begin{abstract}
C) was first detected in mammalian DNA five decades ago. However, it did not take center stage in the field of epigenetics until 2009, when ten-eleven translocation 1 (TET1) was found to oxidize 5-methylcytosine to 5-hmC, thus offering a long-awaited mechanism for active DNA demethylation. Since then, a remarkable body of research has implicated DNA hydroxymethylation in pluripotency, differentiation, neural system development, aging, and pathogenesis of numerous diseases, especially cancer. Here, we focus on DNA hydroxymethylation in smoking-associated carcinogenesis to highlight the diagnostic, therapeutic, and prognostic potentials of this epigenetic mark. We describe the significance of 5-hmC in DNA demethylation, the importance of substrates and cofactors in TET-mediated DNA hydroxymethylation, the regulation of TETs and related genes (isocitrate dehydrogenases, fumarate hydratase, and succinate dehydrogenase), the cell-type dependency and genomic distribution of 5-hmC, and the functional role of 5-hmC in the epigenetic regulation of transcription. We showcase examples of studies on three major smokingassociated cancers, including lung, bladder, and colorectal cancers, to summarize the current state of knowledge, outstanding questions, and future direction in the field.
\end{abstract}

Keywords: 5-hydroxymethylcytosine (5-hmC); cancer; demethylation; isocitrate dehydrogenase (IDH); smoking; ten-eleven translocation (TET); tobacco; transcription

\section{Introduction}

An estimated 1.8 million new cancer cases were diagnosed in the United States in 2020 [1,2]. Cancer is the second leading cause of death in the United States, with an estimated toll of 606,520 American lives in 2020 [2,3]. A strong and substantial body of evidence indicates that the cause of many types of human cancer is tobacco use $[4,5]$. According to the International Agency for Research on Cancer (IARC), tobacco smoke contains nearly 70 carcinogens [6]. Although the percentage of adult cigarette smokers in the United States has declined from $42 \%$ in 1965 to 14\% in 2018 [2,4], there are still 34 million Americans who are current users of tobacco cigarettes $[5,7,8]$. Cigarette smoking alone is responsible for approximately $30 \%$ of all cancer deaths in the United States [1,3]. The U.S. Surgeon General's Report lists 15 types of cancer linked to cigarette smoking, including lung, bladder, bowel (colorectal), liver, pancreas, kidney and ureter (renal), stomach, cervix and ovary, esophagus, and head and neck (mouth, throat, nose, and sinuses) cancers [4].

While many cancers are caused by smoking, not all smokers will develop cancer [1]. A wide range of genetic, epigenetic, and immunological determinants underlie cancer initiation and progression [9-14]. Of these, epigenetic mechanisms have come to the forefront of cancer research, owing to their ability to initiate the disease as well as modulate its clinical course and progression $[10,15,16]$. As such, epigenetic modifications have shown utility for early diagnosis and monitoring of the progression of cancer [16,17]. Given the reversibility of epigenetic changes, they have also shown promise as targets for therapy and prognosticators of response or resistance to treatment $[18,19]$. Whilst the focus of this review is on DNA hydroxymethylation as a prime epigenetic modification with known and emerging 
roles in smoking-associated carcinogenesis [20-24], we refer the readers to comprehensive reviews on other epigenetic alterations, including DNA methylation, histone modifications and variants, microRNA (miRNA) dysregulation, chromatin remodeling, and nucleosome positioning [16,25-30]. Given the extensive body of research on DNA hydroxymethylation and smoking-associated cancers, we have highlighted examples of studies on lung, bladder, and colorectal cancers to summarize the current state of knowledge, outstanding questions, and future directions in this ever-evolving field.

\subsection{DNA Hydroxymethylation: The Rebirth of an Old Cytosine Modification}

5-hydroxymethylcytosine (5-hmC) was first detected in mammalian DNA in 1972 [31]. Research into 5-hmC, however, did not intensify until 2009 [32,33] when ten-eleven translocation 1 (TET1) was found to oxidize 5-methylcytosine (5-mC) to form 5-hmC and its derivatives $[34,35]$. The renewed interest in $5-\mathrm{hmC}$, which is dubbed the sixth DNA base [36] (5-mC being considered the fifth base [37]), has led to a wealth of information on the role of DNA hydroxymethylation in a wide range of biological functions, from DNA demethylation to pluripotency, cell differentiation, neural system development, aging, and pathogenesis of a large variety of diseases, especially cancer [21,22,24,33].

\subsection{DNA Demethylation}

In mammals, DNA demethylation occurs through two distinct pathways: (I) 'active' demethylation and (II) 'passive' demethylation [21,24]. Active demethylation is achieved by TET enzymes whereby TET1, TET2, and TET3 sequentially oxidize 5-mC to 5-hmC, 5-formylcytosine (5-fC), and 5-carboxylcytosine (5-caC), followed by replication-dependent dilution or thymine DNA glycosylase (TDG)-dependent base excision repair (BER) [21,38]. As shown in Figure 1, 5-fC and 5-caC are excised by TDG enzyme and processed by BER, thus resulting in an unmodified cytosine [21,24,38]. Importantly, TDG is highly proficient in recognizing and removing 5-fC and 5-caC from the genome; however, it is highly inefficient in recognizing 5-hmC [39-41]. The substrate specificities of TETs and TDG ensure the stability and abundance of $5-\mathrm{hmC}$ in the genome, supporting the view that 5 -hmC is a persistent epigenetic mark [24,33]. Alternatively, replication-dependent dilution of the oxidation products of 5-mC takes place when 5-hmC, 5-fC, and 5-caC are reversed to unmodified cytosines during DNA replication, a demethylation process also known as 'active modification-passive dilution' (Figure 1) [17,21,42]. During DNA replication, unmodified cytosines are incorporated into the newly synthesized strand, creating hemimodified CpG dinucleotides [43]. A 5-mC:C dyad is recognized by ubiquitin-like with PHD and ring finger domains 1 (UHRF1), which helps recruit DNA methyltransferase 1 (DNMT1) to the hemi-5 mC site [44-46]. This ensures faithful re-establishment of 5-mC on the newly synthesized strand after DNA replication [43]. It has been shown that UHRF1 has lower affinity for 5-hmC:C than 5-mC:C $[47,48]$. In addition, DNMT1 is much less efficient at 5-hmC:C, 5-fC:C, and 5-caC:C dyads than at a 5-mC:C dyad [47-50]. Through successive rounds of DNA replication, a 5-hmC-, 5-fC-, or 5-caC-modified CpG dinucleotide can become demethylated (Figure 1) [21].

As mentioned above, maintenance of DNA methylation is accomplished by DNMTs during DNA replication through methylation of hemimethylated CpG dinucleotides [43,51]. Failure of DNMTs in converting cytosine to 5-mC results in passive DNA demethylation $[24,52]$. It is suggested that deamination of 5-mC to thymine and possibly of 5-hmC to 5-hydroxymethyluracil catalyzed by deaminases, followed by excision repair with TDG, can also lead to the generation of an unmodified cytosine (Figure 1) [24,38,53]. 


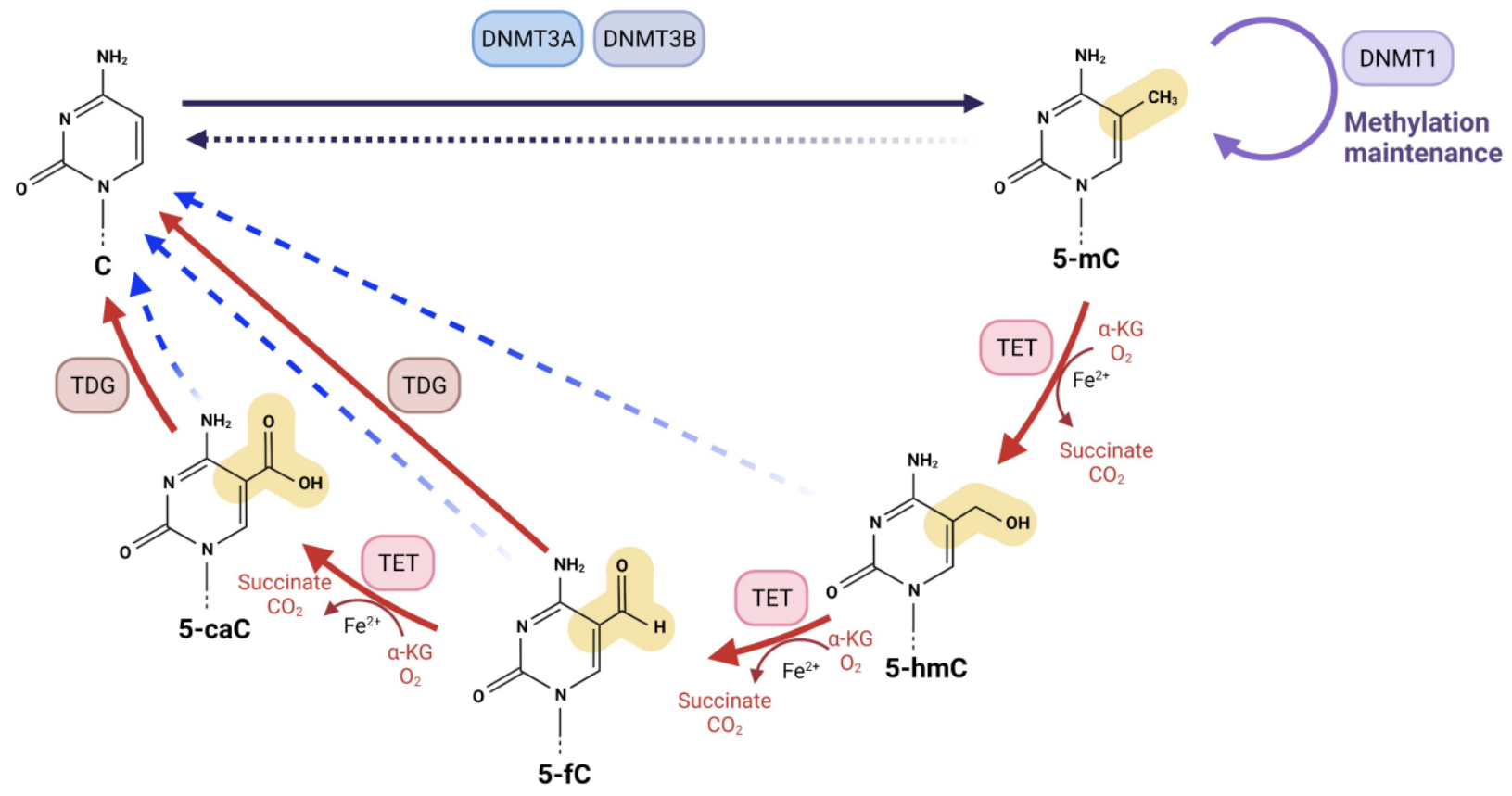

\begin{tabular}{|c|c|c|c|}
\hline De novo methylation & Passive demethylation & $\begin{array}{l}\text { Active demethylation } \\
\text { (replication-independent) }\end{array}$ & $\begin{array}{l}\text { Active demethylation } \\
\text { (replication-dependent) }\end{array}$ \\
\hline
\end{tabular}

Figure 1. DNA demethylation in mammals. The two distinct mechanisms of erasure of 5-mC from the mammalian genome, also known as 'DNA demethylation', are shown. (1) In active demethylation, TET enzymes (TET1, TET2, and TET3) stepwise oxidize 5-mC to 5-hmC, 5-fC, and 5-caC. 5-fC and 5-caC are then excised by TDG and processed by BER, resulting in reversion of 5-mC to cytosine. Alternatively, replication-dependent dilution of 5-mC oxidation products takes place when 5-hmC, 5-fC, and 5-caC are reversed to unmodified cytosine during DNA replication (see Section 1.2 for detailed description). (2) In passive demethylation, failure of DNMTs function results in replacement of $5-\mathrm{mC}$ by cytosine and dilution of 5-hmC content during DNA replication. 5-caC $=5$-carboxylcytosin; 5 -fC $=5$-formylcytosine; 5 -hmC $=5$-hydroxymethylcytosine; 5-mC = 5-methylcytosine; $\alpha-\mathrm{KG}=\alpha$-ketoglutarate; $\mathrm{BER}=$ base excision repair; $\mathrm{C}=$ cytosine; DNMT = DNA methyltransferase; TETs = ten-eleven translocation enzymes (TET1, TET2, and TET3); TDG $=$ thymine DNA glycosylase. Figure was created using the software by BioRender (https: / / biorender.com/, accessed on 8 February 2022).

\section{TET-Mediated Oxidation of 5-mC}

The TET family of enzymes, TET1, TET2, and TET3, in mammalian cells are $\alpha$ ketoglutarate $(\alpha-K G)$-dependent dioxygenases [21,32,54]. The $\alpha$-KG-dependent dioxygenases are a major class of non-heme iron proteins, with nearly 70 members in mammals that catalyze diverse reactions, including hydroxylation, demethylation, ring open expansion, ring closure, and desaturation $[55,56]$. All TET enzymes utilize the same reaction mechanism and cofactors but act on a variety of substrates to catalyze the sequential oxidation of $5-\mathrm{mC}$ to $5-\mathrm{hmC}, 5-\mathrm{fC}$, and $5-\mathrm{caC}[21,57,58]$. The interest in TET proteins has primarily centered around the idea that 5-hmC, 5-fC, and 5-caC could serve as intermediates in DNA demethylation [20-23]. 5-fC and 5-caC are both removed by TDG coupled to BER, resulting in unmodified cytosines and therefore DNA demethylation (see, Figure 1) $[21,39,40,42,59,60]$. However, growing research also shows the additional significance of TET-mediated oxidation of 5-mC in a wide variety of biological functions and diseases, including various types of malignancies [23,24]. 


\subsection{TETs Regulation: The Importance of Substrates and Cofactors Availability}

Similar to other $\alpha-K G$-dependent dioxygenases, TET enzymes require $\alpha-K G$ (also known as 2-oxoglutarate) and molecular oxygen as substrates and $\mathrm{Fe}^{2+}$ as a cofactor to convert 5-mC to 5-hmC, 5-fC, and $5 \mathrm{caC}$ and generate $\mathrm{CO}_{2}$ and succinate [42,61,62]. Many of the TET enzymes also require a reducing agent, such as vitamin $C$, an essential antioxidant that reduces $\mathrm{Fe}^{3+}$ to $\mathrm{Fe}^{2+}$ [21]. Changes in cellular iron concentration have been shown to cause alteration in 5-hmC levels [63]. Moreover, mutations affecting the critical iron-binding residues of TETs are known to reduce the catalytic activity of these enzymes [64]. Vitamin $\mathrm{C}$ is known to stimulate the enzymatic activity of TETs, most likely through acting as a cofactor. Mechanistically, vitamin C directly interacts with the catalytic domain of TET proteins to enhance their enzymatic activity [65-67]. Additionally, vitamin $C$ may promote TET folding to facilitate the recycling of $\mathrm{Fe}^{2+}$ [67].

The tricarboxylic acid cycle (otherwise known as the 'Krebs cycle'), enzyme cytosolic isocitrate dehydrogenase (IDH1), and its mitochondrial homolog (IDH2) are responsible for generating $\alpha-K G$, making them an integral part of the pathway involved in TET-mediated 5 -hmC production [20,61]. IDH1 and IDH2 mutations are heterozygous, and the mutant isoforms generate 2-hydroxyglutarate (2-HG) instead of $\alpha-\mathrm{KG}$ [20]. The accumulation of 2-HG in cells and tissues inhibits enzymes that require $\alpha-\mathrm{KG}$ as a cosubstrate, including the TET proteins [68-71]. Overexpression of IDH1 or IDH2 promotes 5-hmC formation in cells [71,72]. Conversely, downregulation of $I D H 2$, as observed in certain types of cancer, is associated with decreased levels of 5-hmC [72]. Moreover, buildup of succinate or fumarate, which are structurally similar to $\alpha-\mathrm{KG}$ and 2-HG, has been shown to inhibit TETs and other $\alpha$-KG-dependent dioxygenases [68], resulting in loss of 5-hmC [73,74]. Importantly, mutations in the tricarboxylic acid cycle enzymes succinate dehydrogenase (SDH) and fumarate hydratase $(\mathrm{FH})$, which interconvert succinate and fumarate, respectively, are highly common in cancer $[75,76]$. Collectively, the availability of substrates and cofactors can directly affect the reaction kinetics of TETs [21]

\subsection{Post-Transcriptional and Post-Translational Regulation of TETs}

TET-mediated oxidation reactions can be modulated by post-transcriptional and posttranslational regulation of TETs [21]. Following transcription, mRNAs of TETs [77-87] and TDG $[82-84,88]$ can be regulated by miRNAs. Specifically, TETs and TDG are long genes and encode large proteins (180-230 kDa and 75-80 kDa, resp.), which can be targeted post-transcriptionally by miRNAs, particularly in cancer, where the dysregulation of diverse classes of miRNA is very common $[20,21,88]$. After translation, the subcellular localization, chromatin binding, and enzymatic activity of TET proteins can be regulated by covalent modifications, such as ubiquitylation [89], acetylation [90], phosphorylation [91], GlcNAcylation [92-94], and PARylation [95]. Protein levels of TETs can also be regulated by protein-protein interaction [96] and proteolysis [90,97].

\section{Biological Significance of 5-hmC}

TET enzymes have a lower affinity for 5-hmC when compared to 5-mC [21]. Consistent with the poor stability of 5-fC and 5-caC and their amenability to repair by BER, 5 -hmC content in the genome is much higher (10- to 100-fold) than those of its oxidized derivatives [41,58,98-100]. In addition, 5 -hmC has been detected at levels as high as $0.7 \%$ (of total nucleotides) in certain cell types, such as neuronal cells of the central nervous system (CNS) [34,101]. These findings indicate that $5-\mathrm{hmC}$ is not always oxidized to yield derivatives removable by BER [21,38]. Thus, while 5-hmC is important for DNA demethylation [33,38], it may also have other biological functions [20-23].

\subsection{Cell-Type Dependent Distribution of 5-hmC}

Whereas global 5-mC content is relatively consistent across normal adult tissues $(4-5 \%$ of all cytosines), $5-\mathrm{hmC}$ content is moderately low ( $0.4 \%$ of all cytosines and $\sim 10 \%$ of all $\mathrm{mC}$ ) and varies greatly across tissues (between 0.03 and $0.7 \%$ ) $[20,53,101,102]$. The highest 
levels of 5-hmC are found in the adult brain, especially in the hypothalamus and in the cerebral cortex and other compartments $[34,36]$. Of significance, most neuronal cells in the adult brain have ceased to divide mitotically $[103,104]$. The varying abundance of 5-hmC across different cell types, with higher levels in post-mitotic cells (being highest in cells of the CNS) and lower to barely detectable levels in proliferating cells, has been demonstrated in various species, including humans and mice $[32,34,105,106]$. The inverse relationship between 5-hmC content and cell division rate is best exemplified in rapidly dividing cells (with the exception of embryonic stem cells (ESCs) $[53,98,107])$ or highly proliferating cancer cell lines and tumors wherein no or an extremely low level of 5-hmC is detectable $[24,32,108]$.

\subsection{5-hmC and Gene Regulation}

Accumulating data show a prominent role for $5-\mathrm{hmC}$ in the epigenetic regulation of gene expression $[21,33,53,109,110]$. Whether $5-\mathrm{hmC}$ increases or decreases gene transcription is mainly dependent on cell type and its genomic location $[21,33,53,111]$. Abundant $5-\mathrm{hmC}$ is found in gene bodies of active genes, and TET1 is often enriched at the transcription start site (TSS) of genes with high CpG promoters that are occupied by bivalent histone marks, H3K4me3 for transcription activation and H3K27me3 for transcription repression [21,23]. Compelling evidence supports that 5-hmC and TET proteins regulate gene expression through modulating chromatin accessibility of the transcriptional machinery or by affecting repressor binding $[21,24,38]$. This is consistent with the observed high levels of 5-hmC within gene bodies, promoters, and transcription factor (TF) binding sites [105,112-115]. In addition, immunohistochemical analysis has shown that 5-hmC is often accumulated in regions marked by H3K4me2/3 [53,112,116,117]. However, the relationship among 5-hmC, TETs, and gene expression is highly complicated and not always straightforward $[21,33,38,114,118,119]$. For instance, actively transcribed genes show reduced 5-hmC content in their TSS regions, while silenced or lowly expressed genes show abundant $5-\mathrm{hmC}$ at promoters $[21,38,120]$. $5-\mathrm{hmC}$ content in gene bodies is positively correlated to gene expression in certain cell types, whereas the opposite is true in other cell types $[21,38,106]$. Interestingly, many 5 -hmC peaks of ESCs are lost in neural progenitor cells (NPCs), concomitant with a global loss of 5-hmC in the latter cell type, which implies that DNA hydroxymethylation may play a role in the differentiation of ESCs to NPCs [106]. Of significance, TET1 and TET2 are highly expressed in ESCs, which is consistent with the abundance of 5-hmC in these cells [120].

Differences in cell type seem to be a main determinant of the complex relationship between 5-hmC and gene expression [21,38]. For example, despite the abundance of 5-hmC in actively transcribed genes, for a gene with similar expression level in various tissues, there may be a 20-fold change of 5-hmC on the gene body among different tissues [105]. Altogether, the existing data show highly complex and interrelated connections among 5-hmC, TETs, and transcription regulation $[21,33,38,114,118,119]$.

\subsection{Functional Role of 5-hmC in Transcription}

5 -hmC may be involved in regulating gene expression through effects on diverse regulatory elements and processes $[24,33,116,121]$. Distribution of $5-\mathrm{hmC}$ is varied at enhancers, promoters, TSSs, gene bodies, $3^{\prime}$ UTRs, or intragenic regions, consistent with the modulation of 5-hmC patterns by histone modifications, binding proteins of epigenetic marks, and chromatin configuration during cell differentiation and specification $[38,116,122-124]$. 5 -hmC may function as a cis element to promote or repress gene expression by binding to TFs, such as activators or repressors in regulatory regions of genes, or by interacting with histone marks to alter chromatin configuration to switch genes 'on' or 'off' [21,38]. $5-\mathrm{hmC}$ accumulates at the TSS of genes whose promoters are occupied with bivalent histone marks $[115,125]$ and at 'poised' and active enhancers marked with H3K4me1, H3K18ac, and H3K27ac [116,121]. Developmental genes have 'bivalent domains' in promoters and are transcriptionally 'poised' [126]. In pluripotent ESCs, 'bivalent domains' can poise genes 
with both activating (H3K4me3) and repressive (H3K27me3) marks, so that they can be swiftly activated or silenced, depending on the specific differentiation pathway that is taken [126]. The TET-mediated generation and distribution of 5-hmC, modulation of global 5-hmC/5-mC content, and reprogramming of de novo 'bivalent histone code' in CpG island promoters directly influence bivalent domains of the poised genes [127-129].

TET1 forms a complex with polycomb repressive complex 2 (PRC2) at H3K27me3 positive regions in the 'bivalent' state [130], and TET1 depletion impairs PRC2 binding to these targets [112-115,131]. 5-hmC is abundant in both repressed (bivalent, TET1/PRC2cobound) and activated (TET1-only) genes [113], suggesting that 5-hmC plays a role in the machinery responsible for the pluripotency switch [38]. Furthermore, 5-hmC may also modulate alternative splicing to regulate transcription [21]. Of note, alternative splicing is a conserved way of diversifying the transcriptome and proteome, and transcripts from $\sim 90 \%$ of genes undergo alternative splicing [132]. Importantly, 5-hmC is more abundant in constitutive exons than in alternatively spliced exons [133].

\section{The Interplay of TETs, IDHs, and 5-hmC in Cancer}

The role of TET enzymes in human cancer has been most extensively studied in hematopoietic malignancies $[22,23,38]$. Mutations in the TET2 gene are frequent events in these types of cancer [134-136]. TET2 mutations are found in 20\% of acute myeloid leukemias, $20 \%$ of myeloproliferative neoplasms, $45 \%$ of chronic myelomonocytic leukemia, and $15 \%$ of T-cell lymphomas $[22,23,38]$. The studied mutations do not show a complete loss of TET2 function and are primarily missense mutations [137-140]. While TET1 mutations are found at lower frequencies, TET3 mutations are infrequent and have been shown to cause embryonic lethality in mice, suggesting that these mutations may not be tolerated in vivo $[20,140,141]$. We refer the interested readers to elegant reviews on the role of TET enzymes in the pathogenesis of hematopoietic cancers [142-146].

Since TET enzymes are $\alpha$-KG-dependent, they rely on IDH enzymes, which catalyze the oxidative decarboxylation of isocitrate to $\alpha-\mathrm{KG}[21,54]$. Mutations in IDH1 and IDH2 occur frequently in human cancers [147-149]. These mutations are known to affect the active site of IDH enzymes, leading to neomorphic enzyme activity and resulting in the conversion of $\alpha-\mathrm{KG}$ to $2-\mathrm{HG}[148,149]$. 2-HG can then function as a competitive inhibitor of $\alpha$-KG-dependent dioxygenases, including TETs [68]. Similarly to 2-HG, fumarate and succinate, which are known to accumulate in cancer cells due to their deficiency in FH and SDH enzymes [75,76], can compete with $\alpha-K G$ to inhibit TETs $[64,68]$. The inhibition of TET enzymes by 2-HG has been shown to induce hypermethylation of CpG islands at the gene promoters in cancer and is thought to impact proper cell differentiation [147]. Changes in cellular state caused by IDH mutations may then promote malignant transformation [70,71,150-152].

Although mutations in the TET or IDH genes have been found in some malignancies, they are not present in all tumor types $[21,148,149]$. Solid tumors generally show global loss of 5-hmC [22-24]. Oxidative stress has been implicated as a likely event contributing to the global 5-hmC loss observed in human cancers [11,33,90,153]. Oxidative stress is thought to reduce global 5-hmC levels through effects on TET enzymes [33,154]. Of note, oxygen, in addition to $\alpha-\mathrm{KG}$, is a substrate of TET-mediated oxidation [61,62]. Recent findings have shown that oxidative stress leads to post-translation modification of TET2 and reduction of 5-hmC content [21,90].

It has also been demonstrated that hypoxia, a hallmark of cancer, can varyingly change 5 -hmC levels in different cell types $[21,24]$. In response to hypoxia, certain cell types show increased levels of 5-hmC, an effect caused by a hypoxia-inducible factor (HIF)mediated upregulation of TET [155-157]. In other cell types, however, hypoxia causes a reduction in 5-hmC levels without downregulating TET and independently of changes in reactive oxygen species (ROS) production, cell proliferation, and metabolite concentrations, suggesting a direct regulation by oxygen availability [21]. The association between hypoxia and 5-hmC loss is shown in tumor samples from glioblastoma patients and has been 
validated in a mouse breast tumor model [157]. Although the underlying mechanisms of modulation of 5-hmC levels in cancer remain to be fully elucidated, the existing data collectively support a key role for tumor hypoxia in DNA hydroxymethylation in human carcinogenesis [21,24,61,157].

\section{Cigarette Smoking, Oxidative Stress, DNA Hydroxymethylation, and Cancer}

Cigarette smoke contains several thousand chemicals of which many act as oxidants, pro-inflammatory agents, carcinogens, and tumor promoters [6]. Owing to their redox activity, various constituents of cigarette smoke can directly induce oxidative stress [158]. In addition, they can also trigger an inflammatory response, which can, in turn, cause oxidative stress [158-160]. Chronic inflammation and closely related oxidative stress are key components of tumorigenesis and directly linked to carcinogenesis [161-168]. Oxidative stress caused by cigarette smoking is thought to contribute significantly to the development of smoking-associated cancers (reviewed in ref. [167]).

An emerging area of interest is the role of DNA hydroxymethylation modulated by smoking-induced oxidative stress in the initiation and progression of cancer [167]. A recent study by our group has demonstrated significantly reduced global 5-hmC levels in the peripheral blood leukocytes of healthy smokers as compared to nonsmokers, matched for age, gender, and race [169]. The global 5-hmC levels in the study subjects were inversely and statistically significantly correlated to their smoking indices, including pack year and concentrations of plasma cotinine (a major metabolite of nicotine) [169].

While additional data are becoming available [170,171] and new research is underway to comprehensively determine the levels and genomic distribution of 5-hmC in healthy smokers, a wealth of information exists on the DNA hydroxymethylation status in smokingassociated cancers $[23,24]$. By leveraging the existing data on the quantification and mapping of 5-hmC in smoking-associated carcinogenesis, we can determine the potential of this epigenetic modification as a biomarker for the early detection of smoking-related cancers as well as a predictor of response or resistance to treatment. Identifying these mechanistic biomarkers and validating their sensitivity, specificity, and versatility in relevant (patient) populations will not only improve future strategies for diagnosis, treatment, and prognosis of smoking-associated malignancies, but it may also allow assessment of cancer risk in healthy smokers.

\section{Lung Cancer}

Lung cancer is the leading cause of cancer-related deaths worldwide [1,3]. In the United States alone, an estimated 228,820 new cases of lung cancer were diagnosed in 2020, with 135,720 deaths attributable to the disease [2]. The five-year survival rate for lung cancer is $19 \%$. Only $16 \%$ of lung cancer cases are diagnosed at a localized stage when the survival rate is $57 \%$ [2]. This underscores the urgent need for identifying biomarkers of early detection for lung cancer [172-174]. Studies investigating the diagnostic utility of 5 -hmC have found it to be a useful biomarker for the early detection of lung cancer. In addition, 5-hmC has shown promise as a good indicator of lung tumor stage, which is important considering that different stages of lung cancer require different therapies [173]. For example, early stage non-small-cell lung cancer (NSCLC) is treated surgically, whereas patients with locally advanced disease (stage III) require multimodal therapy [174,175]. Personalized treatment based on the patient's tumor stage and clinical conditions has shown to improve the overall survival in lung cancer cases [176,177]. Smoking is the most dominant risk factor for lung cancer, with $80 \%$ of lung cancer deaths linked to smoking [3,4]. Because changes in the genomic distribution and levels of 5-hmC are common in the early stages of lung carcinogenesis-sometimes even prior to clinical manifestation of the disease [22,24,170] — this epigenetic modification may also be exploited as a biomarker for identifying smokers who are at increased risk of developing lung cancer.

Several studies have investigated the genome-wide patterns of 5-hmC in tumor specimens from lung cancer patients (Table 1). Li et al. [178] have used the oxidative bisulfite 
sequencing (oxBS-seq) method to attain a single-base resolution of the hydroxymethylome in three pairs of human lung tumors and normal tissues. They have also used RNA-seq to determine the relationship between $5-\mathrm{hmC}$ and gene expression. The authors reported detection of 5-hmC in promoters, gene bodies, and transcription termination regions, which showed strong positive correlation with gene expression and highly corresponded with H3K4me1 modification, a histone mark associated with active transcription. These findings support the utility of 5-hmC as a marker of active genes and a key determinant of gene expression in lung cancer [178].

Wang et al. [179] have analyzed the quantity and patterns of 5-hmC in eight lung squamous cell carcinoma (LUSC) tissues and adjacent normal tissues using TET-assisted bisulfite-Infinium Methylation EPIC BeadChip array. A global depletion of 5-hmC together with enrichment of hydroxymethylation in $\mathrm{CpG}$ islands and gene upstreams was detectable in tumor tissues as compared to controls. Gene set analysis revealed that the differentially hydroxymethylated genes were likely to converge at pathways involved in the cellular process, biological regulation, and metabolic process. Hierarchical clustering of the significantly differentially hydroxymethylated targets clearly distinguished tumor tissues from controls, supporting the discriminatory power of 5-hmC modeling for lung cancer diagnosis [179].

Two independent studies have quantified 5-hmC in the plasma cell-free DNA (cfDNA) of lung cancer patients as compared to controls. The first study by Song et al. [180] evaluated 5-hmC levels in the cfDNA of 15 lung cancer patients and eight healthy controls using a whole-genome 5-hmC sequencing method (hMe-Seal). Depletion of global 5-hmC was detectable in the cfDNA of lung cancer patients as compared to healthy controls. Among patients, the extent of reduction in global 5-hmC progressively increased as the disease advanced from early stage non-metastatic to late-stage metastatic lung cancer. These findings bear out the predictive value of $5-\mathrm{hmC}$ for lung cancer staging as well as monitoring the progression of the disease. Song et al. also quantified 5-hmC in six other cancer types and found that the 5-hmC signature in lung cancer patients was distinct from not only healthy controls but also from patients diagnosed with other types of cancer [180].

The second study on the quantification of 5-hmC in the plasma cfDNA of lung cancer patients by Zhang et al. [181] employed the same hMe-Seal method to determine genomewide distribution and levels of 5-hmC in 66 NSCLC patients and 67 healthy controls. The authors reported significant 5 -hmC gain in both gene bodies and promoter regions in specimens from lung cancer patients as compared to healthy controls. It is important to note the geographic disparities in the studied populations by Zhang et al. and Song et al., as well as the varying sample sizes and heterogeneity of patients' tumor stage in the respective reports $[180,181]$. Further research in larger and well-defined study populations is warranted to verify the use of $5-\mathrm{hmC}$ detection in cfDNA as a minimally invasive tool for lung cancer diagnosis and prognosis.

Furthermore, mechanistic studies have investigated the role of TET enzymes in lung tumorigenesis. Forloni et al. [182] have reported that oncogenic epidermal growth factor receptor (EGFR) epigenetically silences diverse tumor suppressors in isogenic lung adenocarcinoma cell lines via transcriptional downregulation of TET1 by the C/EBP $\alpha$ transcription factor. Of note, oncogenic EGFR is found in approximately $15 \%$ of lung adenocarcinomas and several other cancer types [183-185]. The authors demonstrated that the inhibition of oncogenic EGFR leads to binding of TET1 to tumor suppressor promoters and induces their re-expression through active DNA demethylation [182]. They also showed that ectopic expression of TET1 potently inhibits tumor growth in soft agar assays and significantly reduces tumor formation in athymic nude mice. In addition, small/short hairpin RNAs (shRNAs)-induced TET1 knockdown confers resistance to EGFR inhibitors in lung cancer cells. Loss of TET1 expression or mislocalized cytoplasmic TET1 is detectable in a substantial percentage of patient-derived lung cancer samples $(\sim 44 \%)$, suggesting that TET1 is likely inhibited in lung cancer [182]. Altogether, these results indicate that the disruption of TET1 function can lead to the demethylation-dependent inactivation of 
tumor suppressor genes in lung cancer as well as adversely affect patients' response to therapeutic options.

\section{Bladder Cancer}

In the United States, urinary bladder cancer is the fourth most common cancer in men, with an estimated 81,400 new cases and 17,980 deaths in 2020 [2]. The overwhelming majority of bladder cancer cases $(\sim 95 \%)$ are transitional cell carcinomas, which are primarily non-muscle invasive at the time of diagnosis and amenable to surgical treatment [186-188]. However, up to $80 \%$ of the treated cases will recur, of which $45 \%$ will progress to invasive cancer within five years $[186,187,189]$. The main screening method for bladder cancer is examination of the bladder wall with a cystoscope, which is both invasive and costly $[187,190]$. This method may also miss up to $30 \%$ of malignant cases $[187,190]$. Thus, there is a need for more accurate, efficient, and preferably non- or minimally-invasive methods to screen for bladder cancer [188,191-193]. Cigarette smoking is a major risk factor for bladder cancer $[6,194]$. Approximately half of all bladder cancer patients have a history of exposure to cigarette smoke [194]. Currently, the lag time between initial exposure to cigarette smoke and bladder cancer diagnosis is 20-30 years [1,3]. Studies investigating DNA hydroxymethylation in urological malignancies have found changes in the quantity and patterns of 5-hmC during early stages of these diseases (Table 1). Therefore, 5-hmC has the potential to be used as an epigenetic biomarker for the early detection of bladder cancer and a screening tool for identifying smokers who are at elevated risk of developing this malignancy.

Peng et al. [195] investigated the genome-wide patterns and levels of 5-hmC in matched bladder cancer and normal bladder tissues from 135 urothelial carcinoma patients as well as in bladder cancer cell lines and controls. Additionally, they evaluated the modulatory effects of vitamin C, a cofactor for TET enzymes, on DNA hydroxymethylation and inhibition of the malignant phenotype in both in vitro and in vivo models of bladder cancer. A global loss of 5-hmC was detected in bladder cancer tissues as compared to controls by both immunohistochemistry (IHC) and immunodot blot assays. Likewise, reduced global 5-hmC content was detectable in bladder cancer cell lines (T24, 5637, UMUC-3, and J82 cells) as compared to controls (Hum-u007: human normal bladder primary epithelial cells and SV-HUC-1: immortalized normal human urinary epithelial cells) by immunodot blot assay. Among bladder cancer patients, lower global 5-hmC levels correlated with higher tumor stage, lymphatic metastasis, and shorter overall survival, suggesting that the loss of 5-hmC is critical for bladder cancer progression, leading to poor clinical outcomes. Genome-wide mapping of 5-hmC was performed in paired bladder tumors and adjacent normal tissues using a hydroxymethylated DNA immunoprecipitation approach coupled with deep sequencing (hMeDIP-seq). A significant decrease in 5-hmC levels was observed within genes or in the regions $2 \mathrm{~kb}$ up- or downstream of the genes in bladder tumors as compared to control tissues. The differentially hydroxymethylated loci identified in bladder tumors mapped to 5,843 genes, with more than half of the targets being located either in exons $(10.3 \%)$ or introns (58.9\%) and $6.45 \%$ localizing to promoters. Kyoto Encyclopedia of Genes and Genomes (KEGG) pathway enrichment and gene ontology (GO) analyses revealed that the differentially hydroxymethylated genes in bladder tumors are closely associated with various cancer-related pathways. It was also shown that in vitro vitamin $\mathrm{C}$ treatment increases 5-hmC levels and inhibits malignant phenotypes in bladder cancer cell lines, as determined by cell proliferation analysis and apoptosis and colony formation assays. Similar results were found in vivo wherein intraperitoneal injection of vitamin $\mathrm{C}$ in a mouse xenograft model with human urinary bladder cancer T24 cells resulted in increased 5-hmC levels, reduced tumor growth, and decreased tumor burden [195].

Munari et al. [196] utilized an IHC staining method to evaluate global 5-hmC levels in tumor specimens and adjacent benign tissues from 55 patients with urothelial cell carcinoma of the bladder. A significant reduction in global 5-hmC levels was observed in urothelial cell carcinoma samples as compared to controls. No difference in global 5-hmC content 
was detectable between superficial and invasive lesions, suggesting that a loss of 5-hmC may represent an early event in bladder carcinogenesis. The global 5-hmC loss was not correlated with tumor grade or stage or the patients' prognosis. However, the authors acknowledged that the study was not adequately powered to detect small prognostic differences based on 5-hmC levels because the number of progression and disease-specific death events were overall low [196]. The use of genome-wide sequencing-based approaches should facilitate the detection of site-specific changes in 5-hmC that may otherwise not be identifiable when using IHC analysis in small sample sizes.

The role of TET enzymes in bladder cancer progression and metastasis has been investigated in multiple studies. Zhu et al. [197] identified a new TET1/USP28/CD44/RhoGDI $\beta$ pathway, which is responsible for the oncogenic role of autophagy-related gene 7 (ATG7) in invasion, metastasis, and stem-like properties in human bladder cancer cells (T24T). Specifically, ATG7 overexpression inhibits AU-rich element RNA-binding protein 1 (AUF1) expression, which stabilizes TET1 mRNA to increase its protein expression. Upregulated TET1 then directly demethylates the ubiquitin specific peptidase 28 (USP28) promoter, thereby enhancing USP28 transcription and expression. Binding of USP28 to CD44 standard (CD44s) protein leads to removal of the ubiquitin group from the ubiquitinated CD44s protein, resulting in the stabilization of CD44s protein to mediate the stem-like property of human bladder cancer cells. Furthermore, CD44s inhibits RhoGDI $\beta$ degradation, which in turn promotes human bladder cancer invasion and lung metastasis [197].

Hu et al. [198] reported a potential role of the X-inactive specific transcript (XIST)-TET1p53 regulatory network in cell proliferation, migration, and apoptosis in bladder cancer. Importantly, TP53 mutations are found in nearly half of all transitional cell carcinomas of the bladder, most frequently in high-grade invasive tumors [199]. The authors demonstrated that TET1 binds to the promoter region of the TP53 tumor suppressor gene and promotes its expression in bladder cancer cells (T24), whereas XIST inhibits the expression of TP53 by binding to TET1. Knockdown of XIST significantly suppresses cell proliferation and migration and induces apoptosis in bladder cancer cells, whereas overexpression of XIST has the opposite effects. The TP53-mediated cell proliferation and migration and apoptosis in bladder cancer were suggested to be modulated by XIST-related inhibition of TET1 binding to TP53 promoter, resulting in hypermethylation and decreased expression of this tumor suppressor gene [198].

\section{Colorectal Cancer}

Colon and rectal (colorectal) cancers are the third leading sites of new cancer and the second deadliest malignancy, with an estimated 1.9 million incidence cases and 0.9 million deaths worldwide in 2020 [190]. In the United States, 104,610 new cases of colon cancer and 43,340 new cases of rectal cancer, with 53,200 related deaths, have been estimated for the year 2020 [1]. The five-year survival rate for colorectal cancer is $64 \%$ [200,201]. The survival rate, when the cancer is at a localized stage, is $90 \%$; however, only $39 \%$ of patients are diagnosed at this stage [200,201]. Additionally, both the incidence and death rates for colorectal cancer among adults younger than 55 are rising [2]. Currently, screening is recommended for people over the age of 45; however, the choice of colonoscopy, a routinely used and highly invasive screening method, makes this recommendation not widely adoptable [201,202]. The increase in cases among younger adults and lack of non-invasive screening tools highlight the need for novel biomarkers of early detection for colorectal cancer [202,203]. Over half of colorectal cancers in the United States are attributable to modifiable risk factors. Twelve percent of the incidence cases and $11 \%$ of the colorectal cancer deaths are directly linked to cigarette smoking [1,2]. Screening smokers to determine the 'at risk' individuals for colorectal cancer development may enable earlier detection of the disease, thus improving survival from this deadly malignancy.

The roles of 5-hmC and TET enzymes in the initiation and progression of colorectal cancer have been investigated as a means to identify diagnostic and prognostic biomarkers for this disease (Table 1). Dziaman et al. [154] quantified 5-hmC levels in samples from 
colorectal cancer (CRC) patients ( $n=97$; paired tumors and normal colonic tissues), as well as patients with predisposing conditions, including benign polyps/colon adenomas (AD, $n=39$ ) and inflammatory bowel disease (IBD, $n=49$ ) [203-205]. In addition, they determined the expressions of TETs at mRNA and protein levels by reverse-transcription quantitative polymerase chain reaction (RT-qPCR) and IHC, respectively, and measured 8-oxo-7,8-dihydro-2'-deoxyguanosine (8-oxodG), as a marker of oxidative stress [167], in the samples. Using a highly specific and sensitive isotope-dilution automated online two-dimensional ultra-performance liquid chromatography with tandem mass spectrometry (2D-UPLC-MS/MS), they detected significantly lower levels of 5-hmC in CRC, followed by $\mathrm{AD}$ and IDB specimens as compared to normal colonic tissues. To find the relationship between 5-hmC loss and tumor progression, the levels of 5-hmC in CRC samples were correlated to their corresponding tumor stages, from ' $\mathrm{A}$ ' to ' $\mathrm{D}$ '. The significant decrease in 5-hmC content was characteristic for early-stage tumors (stage A), whereas no further reduction in 5-hmC levels was observed in advanced-stage tumors as the disease progressed. Quantification of 8-oxodG by 2D-UPLC-MS/MS showed significantly increased levels of this lesion in IBD and AD samples as compared to both CRC and normal colonic tissues. The elevated levels of 8-oxodG in both IBD and AD [154], which are considered precursor conditions for CRC [203-205], are consistent with the proposed role of oxidative stress in the initiation of carcinogenesis [161-168]. Additionally, 8-oxodG may serve as a demethylation signal whereby the base excision repair enzyme, 8-oxoguanine DNA glycosylase (OGG1), bound to this lesion can recruit TET1, which in turn promotes DNA demethylation in response to DNA damage caused by oxidative stress [206]. This may, at least, partially explain the significant reductions in 5-hmC levels concomitant with the increased 8-oxodG levels found in AD and IBD samples as compared to normal colonic tissues. Moreover, the expressions of both TET1 and TET2 mRNA in CRC and AD samples were significantly lower than those in normal colonic tissues. Reduced expressions of TET1 and TET2 proteins ( $p=0.003$ and $p=0.06$, respectively) in CRC than normal colonic tissues were also confirmed by IHC analysis. No changes in expression of TET3 at mRNA or protein level were observed in the analyzed samples [154].

Chapman et al. [207] investigated whether 5-hmC plays a role in the regulation of differentiation in colonocytes. The authors measured changes in the levels and genomic distribution of 5-hmC in T84 colon adenocarcinoma cells during cell-cell adhesion-initiated differentiation. They demonstrated that total 5-hmC levels increase during T84 cell differentiation, as determined by immunodot blot assay. Mapping of 5-hmC in the genomic DNA of cells at increasing intervals during differentiation (days $0,4,12$, and 15) by the hMe-Seal method revealed progressive enrichment of 5-hmC at CpG islands, CpG shores, promoters, and gene bodies. KEGG pathway analysis showed that 5 -hmC enriched regions localize to genes involved in epithelial barrier function, including focal adhesion, adherens junctions, regulation of actin cytoskeleton, and endocytosis. Homer motif analysis of regions with 5-hmC peaks predicted that they bind the HNF4A, RXRA, and CDX2 transcription factors, which are known to regulate intestinal development. Examination of HNF4A binding sites of VAV2 and GNA12 by TET-assisted bisulfite sequencing (TAB-seq) confirmed that the gain of 5-hmC is accompanied by demethylation at the binding sites of these oncogenes. As HNF4A binding sites have been associated with regions losing methylation in intestinal differentiation [208], the observed formation of 5-hmC at these sites may provide a mechanism for this association. RNA-seq and KEGG pathway analyses showed that genes associated with the mitogen-activated protein kinase (MAPK) signaling pathway are induced over the course of differentiation in T84 cells, whilst numerous metabolic and disease-associated pathways are repressed, simultaneously. The upregulated genes show higher 5-hmC content than genes that are downregulated or exhibit unchanged expression over the time course of differentiation. A reverse analysis examining expression as a function of 5-hmC further confirmed that highly hydroxymethylated genes are more overexpressed and genes with the highest levels of 5-hmC are more likely to be induced and have a greater median fold change than genes with lower 5 -hmC levels. The observed 
association of 5-hmC with highly expressed and induced genes suggests that 5-hmC has an important role in the regulation of gene expression during differentiation of colonocytes. Furthermore, the authors showed that TET1 expression is induced during the time course of differentiation in T84 cells, and TET1 knockdown alters the expression of genes coding for proteins targeted to the cell membrane and extracellular space, thus inhibiting barrier formation of colonocytes. Comparison of genomic regions covered by 5 -hmC in differentiated T84 cells in vitro and primary human colonocytes $(n=2)$ revealed a similar pattern of distribution, whilst a direct correlation was found between gene-specific 5-hmC changes and alterations in gene expression in human colon cancer tissues [207].

Li et al. [209] performed genome-wide profiling of 5-hmC in the genomic DNA (gDNA) of paired tumor and adjacent tissues collected from 80 colorectal cancer patients and in plasma cfDNA samples from patients and healthy controls $(n=90)$. Global 5-hmC levels were markedly decreased (on average an 85\% drop) in the gDNA of tumors as compared to adjacent healthy tissues, as determined by ultra-sensitive capillary electrophoresiselectrospray ionization-mass spectrometry. A more limited decrease in global 5-hmC levels was detected in the cfDNA of colorectal cancer patients as compared to healthy controls, consistent with the low proportions of tumor-derived DNA in the total cfDNA pool. In the cfDNA of cancer patients as compared to controls, 5-hmC was enriched within gene bodies and DNase I sensitive sites, whereas it was depleted at TSS, CpG islands, and TF binding sites relative to the flanking regions. This implies that 5-hmC accumulates at positions surrounding TFs at active transcription sites. This was confirmed in the same samples where 5-hmC was enriched in regions marked by permissive histone modifications, such as $\mathrm{H} 3 \mathrm{~K} 27 \mathrm{ac}, \mathrm{H} 3 \mathrm{~K} 4 \mathrm{me1}$, and H3K9me1, whereas it was underrepresented in regions marked by the repressive modification $\mathrm{H} 3 \mathrm{~K} 9 \mathrm{me} 3$. The average 5 -hmC profiles of cfDNA were distinct from those of tissue and white blood cell gDNA, which might be ascribed to the different cells of origin and/or varying extent of DNA degradation in cell-free circulation. Among gDNA 5-hmC profiles, variations attributable to tissue identity (colon tissues vs. white blood cells) were dominant over variations related to disease status (cancer patients vs. healthy individuals and tumors vs. adjacent normal tissues). Presumably, when gDNA from tumor tissue is released into plasma and diluted with the large quantities of background cfDNA derived from various other tissues, the tumor signal detected at a given locus is determined by the order of locus-, tissue-, and disease-specific variations. A model-based classifier using differentially hydroxymethylated loci identified in cfDNA and gDNA was developed, which predicted disease status, with high sensitivity (80-88\%) and specificity (83-100\%) in independent subpopulations of patients and healthy controls. This classifier also performed better than the conventional biomarkers (including carcinoembryonic antigen (CEA), alpha-fetoprotein (AFP), carbohydrate antigens (CA125, CA15-3, CA19-9, and CA72-4), cytokeratin 19, and neuron-specific enolase (NSE)) and epidemiological risk factors (including indices of overweight, obesity, and alcohol consumption and previous history of cancer) when predicting colorectal cancer. RNA-seq analysis of two tumors from colorectal cancer patients and paired adjacent tissues showed a significant correlation between changes in gene expression levels and alterations in 5-hmC levels in gene bodies in tumor samples $\left(p=9.8 \times 10^{6}\right)$. DAVID pathway analysis revealed that genes with altered 5-hmC levels in tumor gDNA or cancer cfDNA were enriched in cancer- and metastasis-related pathways [209].

Rawluzko-Wieczorek et al. [210] investigated alterations in mRNA levels and promoter methylation of TET1, TET2, and TET3 in primary cancerous and histopathologically unchanged colorectal tissues from a cohort of 113 patients. Quantitative RT-PCR analysis showed significantly reduced TET1, TET2, and TET3 transcript levels in cancerous tissues as compared to histopathologically unchanged tissues. Importantly, patients with high TET2 mRNA levels in histopathologically unchanged tissues had favorable overall survival and disease-free survival outcomes. This implies that TET2 mRNA levels may have prognostic potential for CRC patients' relapse and survival. Furthermore, bisulfite sequencing confirmed promoter hypermethylation in TET1 in cancerous tissues as compared to 
histopathologically unchanged tissues in a small portion of patients $(12 / 113=10.6 \%)$. No DNA methylation was detected in cancerous or histopathologically unchanged tissues at the TET2 and TET3 promoters [210].

Neri et al. [211] analyzed the levels of TET1 mRNA and 5-hmC in eight pairs of primary colon cancers and adjacent healthy tissues. Strong reduction in both TET1 transcript and 5-hmC levels was detected in cancer tissues as compared to controls by RT-qPCR and immunodot blot assays, respectively. Downregulation of TET1 was independent of tumor stage and the histopathological grade. The authors confirmed this finding by analyzing a metadata set of colon, breast, lung, and rectum primary tumors of varying stages (stages I to IV). Analysis of the genes differentially expressed in this cohort of 887 adenocarcinomas revealed that TET1, but not TET2 or TET3, was strongly downregulated in tumors since stage I. This indicates that TET1 downregulation is an early event in colon tumorigenesis. Additional experiments showed that TET1 expression and 5-hmC levels were easily detectable in human colon tissues and in normal epithelial colon cells (CCD), whereas no detectable levels of TET1 transcript or 5-hmC were observed in five different colorectal cancer cell lines (Colo205, HCT116, HT29, SW48, and Caco-2). Silencing of TET1 in the normal CCD cells using two different shRNAs resulted in increased cell proliferation, suggesting that TET1 has a role in the control of cell growth. Rescuing experiments showed that re-expression of TET1 in the TET-silenced cells induced a full recovery of 5-hmC level and reduced cell proliferation rate. To demonstrate the effects of TET1 re-expression on the growth of colon cancer cells, Caco-2 and SW48 human colorectal carcinoma cell lines stably expressing TET1 under the control of a doxycycline (DOX)-inducible promoter were generated. Of note, re-expression of TET1 did not alter TET2 or TET3 expression in these cells. Upon treatment of the cells with DOX, elevation of 5-hmC levels concomitant with a strong reduction in growth rates were observed in both cell lines. These effects were due to the enzymatic activity of TET1, as the catalytically dead mutant (hydroxylase-deficient mutant TET1-H1672Y/D1674A) was not able to interfere with cell growth in vitro. To investigate whether TET1 plays a role in tumor growth in vivo, nude mice were injected with Caco-2 and SW48 cell lines and subsequently treated with DOX to induce TET1 expression. The size and weight of xenografts expressing TET1 were markedly smaller than those in the control group, wherein TET1 was not induced. Growth of the tumor xenografts was blocked not only when TET1 was induced early after the tumor cells' inoculation (with both cell lines) but also several days afterwards when the tumors were already established. Functional experiments showed that TET1 inhibits cancer cells' growth by repressing the WNT signaling pathway via demethylation of the promoters of the WNT inhibitors, Dickkopf Homolog 3 (DKK3) and Dickkopf Homolog 4 (DKK4), as reflected by the increase in 5 -hmC and decrease in 5-mC levels in promoters of the respective genes in DOX-treated Caco- 2 and SW48 cells as compared to controls. Rescue experiments in colon cancer cell lines in which the DKK3 and DKK4 genes were silenced and TET1 was re-expressed showed that knockdown of both genes restored the cell growth inhibition by TET1 expression [211]. Collectively, these data indicate that DNA hydroxymethylation mediated by TET1 controlling the WNT signaling is a key player of tumor growth in colon cancer. TET1 reactivation, although challenging, may represent a novel therapeutic approach for colon cancer and other types of malignancy. 
Table 1. Summary results of selected studies on DNA hydroxymethylation and three major smokingassociated cancers (i.e., lung, bladder, and colorectal cancers).

\begin{tabular}{ccccc}
\hline Study & Cancer Type & \multicolumn{1}{c}{ Samples } & Method(s) & \multicolumn{1}{c}{ Key Findings } \\
\hline Li et al. & Lung & $\begin{array}{l}\text { Tumors from lung } \\
\text { cancer patients and } \\
\text { adjacent normal } \\
\text { tissues }(n=3)\end{array}$ & $\begin{array}{l}\text { RNA-seq } \\
\text { oxBS-seq and }\end{array}$ & $\begin{array}{l}\text { 5-hmC was significantly enriched in promoters, gene } \\
\text { bodies, and transcription termination regions. } \\
\text { There was strong positive correlation between 5-hmC } \\
\text { and gene expression levels. } \\
\text { The genomic distribution of 5-hmC highly } \\
\text { corresponded with the active histone mark H3K4me1. }\end{array}$ \\
\end{tabular}

Ref.

Lung squamous cell carcinomas and adjacent normal

TAB-EPIC tissues $(n=8)$
- Global loss of 5-hmC together with enrichment of 5-hmC in CpG islands and gene upstreams was detected in tumors as compared to normal tissues.

- The differentially hydroxymethylated genes converged at pathways involved in cellular process, biological regulation, and metabolic process.
Wang et al. Lung

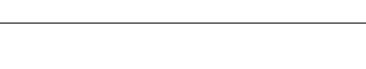

Song et al. Lung

Plasma cfDNA

from lung cancer

patients $(n=15)$

and healthy

controls $(n=8)$
hMe-Seal

Depletion of global 5-hmC levels was detected in cfDNA of lung cancer patients as compared to healthy controls.

The extent of reduction in global 5-hmC levels in patients' cfDNA increased progressively as the disease advanced from early-stage non-metastatic to late-stage metastatic lung cancer.

\begin{tabular}{llll}
\hline & & $\begin{array}{l}\text { Plasma cfDNA } \\
\text { from non-small-cell } \\
\text { lung cancer } \\
\text { patients }(n=66) \\
\text { and healthy } \\
\text { controls }(n=67)\end{array}$ & hMe-Seal \\
\hline Forloni et al. Lung & Lung & $\begin{array}{l}\text { Lung } \\
\text { adenocarcinoma } \\
\text { cell lines }\end{array}$ & $\begin{array}{l}\text { shRNA } \\
\text { knockdown } \\
\text { assays, soft } \\
\text { agar assay, and } \\
\text { tumorigenicity in } \\
\text { nude mice }\end{array}$ \\
\hline
\end{tabular}

- $\quad$ Significantly increased 5-hmC levels were found in gene bodies and promoter regions in cfDNA of lung cancer patients as compared to controls.$$
\text { cancer patients as compared to controls. }
$$

- Oncogenic EGFR was shown to silence multiple tumor suppressors in lung cancer cell lines via transcriptional downregulation of TET1 by the $\mathrm{C} / \mathrm{EBP} \alpha$ transcription factor.

- Global loss of 5-hmC was detected in tumor tissues from bladder cancer patients as well as bladder cancer cell lines as compared to controls.

- 5-hmC levels were significantly decreased within

Bladder tumors and matching normal tissues from urothelial

Peng et al. Bladder $(n=135)$ andbladder cancer cell lines and controls
hMeDIP-seq, IHC, IDB, MTS cell proliferation assay, apoptosis assay, colony formation assay, and xenograft mouse tumorigenicity genes or in the regions $2 \mathrm{~kb}$ up- or downstream of the genes in bladder tumors as compared to controls.

- Depletion of global 5-hmC levels in bladder cancer patients correlated with higher tumor stage, lymphatic metastasis, and shorter overall survival.

- The differentially hydroxymethylated genes converged on molecular pathways involved in cancer.

- In vitro treatment of bladder cancer cell lines with vitamin $\mathrm{C}$ resulted in increased 5-hmC levels and inhibition of malignant phenotypes.

- $\quad$ In vivo treatment of mice with vitamin $C$ by i.p. injection resulted in increased 5 -hmC levels, reduced tumor growth, and decreased tumor burden.

Tumors and adjacent benign tissues from patients with urothelial cell carcinoma of the bladder $(n=55)$
- Global 5-hmC levels were significantly reduced in tumors from patients as compared to control tissues.

- $\quad$ The reduction in global 5-hmC levels was not different between superficial tumors and invasive tumors.

IHC

- The extent of reduction in global 5-hmC levels was not correlated to tumor grade or stage, or patients' prognosis. 
Table 1. Cont.

\begin{tabular}{|c|c|c|c|c|c|}
\hline Study & Cancer Type & Samples & Method(s) & Key Findings & Ref. \\
\hline Zhu et al. & Bladder & $\begin{array}{l}\text { Bladder cancer } \\
\text { cell lines }\end{array}$ & $\begin{array}{l}\text { shRNA } \\
\text { knockdown } \\
\text { assays, rescue } \\
\text { experiments for } \\
\text { gene expression, } \\
\text { MSP, RIP, } \\
\text { RT-PCR, Western } \\
\text { blot, cell } \\
\text { migration, } \\
\text { invasion, and } \\
\text { lung metastasis } \\
\text { assays }\end{array}$ & $\begin{array}{l}\text { - The TET1/USP28/CD44/RhoGDI } \beta \text { pathway was } \\
\text { identified as the regulator of the oncogenic activities of } \\
\text { ATG7 for stem-like property, invasion, and lung } \\
\text { metastasis of human bladder cancer cells. }\end{array}$ & [197] \\
\hline Hu et al. & Bladder & $\begin{array}{l}\text { Bladder cancer } \\
\text { cell lines }\end{array}$ & $\begin{array}{l}\text { RIP, ChIP, } \\
\text { RT-qPCR, } \\
\text { Western blot, and } \\
\text { cell proliferation, } \\
\text { migration, and } \\
\text { invasion assays }\end{array}$ & $\begin{array}{l}\text { - The XIST-TET1-p53 regulatory network was identified } \\
\text { as a regulator of cell proliferation, migration, and } \\
\text { apoptosis in bladder cancer cells. }\end{array}$ & [198] \\
\hline $\begin{array}{l}\text { Dziaman } \\
\text { et al. }\end{array}$ & Colorectal & $\begin{array}{l}\text { Tumors and } \\
\text { adjacent normal } \\
\text { colonic tissues } \\
\text { from patients with } \\
\text { CRC }(n=97), \text { colon } \\
\text { samples from AD } \\
(n=39), \text { and IBD } \\
\text { patients }(n=49)\end{array}$ & $\begin{array}{l}\text { 2D-UPLC- } \\
\text { MS/MS, } \\
\text { RT-qPCR, and } \\
\text { IHC }\end{array}$ & $\begin{array}{l}\text { - } 5 \text {-hmC levels were significantly lower in tumor tissues } \\
\text { from CRC patients, followed by samples from AD and } \\
\text { IDB patients as compared to normal colonic tissues. } \\
\text { Whereas early stage ('A') tumors had significant } \\
\text { reduction in 5-hmC content, no further decrease in } \\
\text { 5-hmC levels was found in advanced stage } \\
\text { tumors ('B-D'). } \\
\text { TET1 and TET2 mRNA expressions were significantly } \\
\text { decreased in CRC and AD samples as compared to } \\
\text { normal colon samples. } \\
\text { Reduced expressions of TET1 and TET2 proteins were } \\
\text { observed in CRC samples as compared to normal } \\
\text { colonic tissues. } \\
\text { No changes in expression of TET3 at mRNA or protein } \\
\text { level were observed in the analyzed samples. } \\
\text { The levels of biomarker of oxidative DNA damage } \\
\text { (8-oxodG) were significantly increased in samples from } \\
\text { IBD and AD patients as compared to samples from } \\
\text { CRC patients and normal colonic tissues. }\end{array}$ & [154] \\
\hline
\end{tabular}

- Global 5-hmC levels increased during differentiation of colon cancer cells.

- 5-hmC levels progressively increased at CpG islands, CpG shores, promoters, and gene bodies in colon cancer cells during differentiation (days $0,4,12$, and 15).

- $\quad$ The 5-hmC enriched regions during differentiation of colon cancer cells localized to genes involved in epithelial barrier function (i.e., focal adhesion, adherens junctions, regulation of actin cytoskeleton, and endocytosis)

\section{Colon}

Chapman Colorectal et al. s and primary human colonocytes
hMe-Seal, IDB TAB-seq, RNA-seq, and shRNA knockdown assays
- $\quad$ Genes associated with MAPK signaling pathway were induced during differentiation of colon cancer cells, whereas numerous metabolic and disease-associated pathways were repressed, simultaneously.

- $\quad$ The upregulated genes had higher 5-hmC content than genes that were downregulated or exhibited unchanged expression during differentiation of colon cancer cells.

- $\quad$ TET1 expression was induced during differentiation of colon cancer cells.

- $\quad$ TET1 knockdown in colonocytes changed the expression of genes coding for proteins targeted to cell membrane and extracellular space, thus inhibiting barrier formation.

- $\quad$ Gene-specific 5-hmC changes were directly correlated to expression changes in the corresponding genes in colon cancer tissues. 
Table 1. Cont.

\begin{tabular}{|c|c|c|c|c|c|}
\hline Study & Cancer Type & Samples & Method(s) & Key Findings & Ref. \\
\hline Li et al. & Colorectal & $\begin{array}{l}\text { Tumors and } \\
\text { adjacent normal } \\
\text { tissues and plasma } \\
\text { cfDNAs from CRC } \\
\text { patients }(n=80) \\
\text { and plasma } \\
\text { cfDNAs from } \\
\text { healthy controls } \\
(n=90)\end{array}$ & $\begin{array}{l}\text { CE-ESI-MS and } \\
\text { RNA-seq }\end{array}$ & 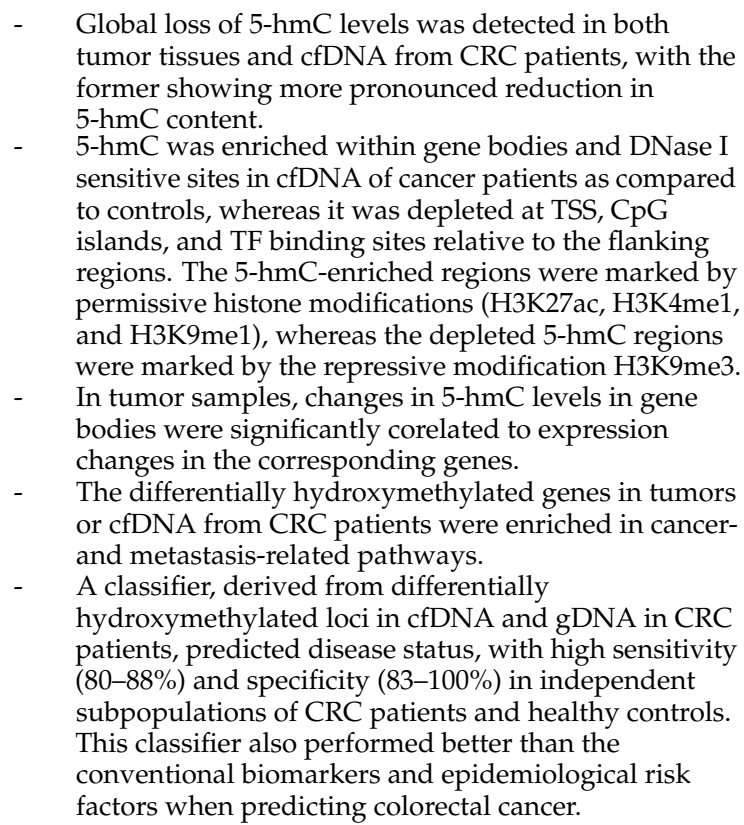 & [209] \\
\hline
\end{tabular}

\section{Primary} tumors and

RawluzkoWieczorek et al. Colorectal histopathologically unchanged tissues from CRC patients $(n=113)$
RT-qPCR and

bisulfite sequencing
- $\quad$ TET1, TET2, and TET3 transcript levels were significantly reduced in tumors as compared to control tissues.

- High TET2 mRNA levels in histopathologically normal tissues from CRC patients associated with favorable overall survival and disease-free survival.

In tumor samples, promoter hypermethylation was found only in TET1 $(12 / 113=10.6 \%)$ but not in TET2 or TET3.

- $\quad$ TET1 transcript and 5-hmC levels were both reduced in tumor tissues as compared to controls.

- Downregulation of TET1 was independent of patients' tumor stage and histopathological grade.

- $\quad$ No detectable levels of TET1 expression or 5-hmC were found in CRC cells lines.

Primary tumors and adjacent

healthy tissues

Neri et al. Colorectal patients $(n=8)$ and normal epithelial colon cells and CRC cell lines
IDB, RT-qPCR shRNA knockdown assays, and xenograft mouse tumorigenicity
Silencing of TET1 in normal epithelial colon cells resulted in increased cell proliferation, whereas re-expression of TET1 in colon cancer cells markedly increased 5-hmC levels and suppressed growth rate.

Mice injected with DOX-induced TET1-expressing colon cancer cells developed significantly smaller tumors (both in size and weight) than counterpart mice injected with non-induced TET1 cells.

- $\quad$ Functional studies identified DNA hydroxymethylation mediated by TET1-controlled WNT signaling as a key player of tumor growth in colon cancer.

Given the extensive body of literature, we have selected illustrative examples of studies on lung, bladder, and colorectal cancers, which are three major smoking-associated cancers. oxBS-seq = oxidative bisulfite sequencing; TAB-EPIC = TET-assisted bisulfite-Infinium Methylation EPIC BeadChip array; cfDNA = cell-free DNA hMe-Seal = selective chemical labeling of 5-hmC with biotin for genome-wide detection; shRNA = small/short hairpin RNA; EGFR = epidermal growth factor receptor; IHC = immunohistochemistry; IDB = immunodot blot assays; hMeDIP-seq = hydroxymethylated DNA immunoprecipitation with deep sequencing; MSP = methylationspecific polymerase chain reaction; RIP $=$ RNA immunoprecipitation; RT-qPCR = reverse-transcription quantitative polymerase chain reaction; ATG7 $=$ autophagy-related gene 7 ; ChIP $=$ chromatin immunoprecipitation; $\mathrm{XIST}=\mathrm{X}$-inactive specific transcript; $\mathrm{CRC}=$ colorectal cancer; $\mathrm{AD}=$ benign polyps/colon adenomas; IBD = inflammatory bowel disease; 2D-UPLC-MS / MS = two-dimensional ultra-performance liquid chromatography with tandem mass spectrometry; 8-oxodG $=8$-oxo-7,8-dihydro-2'-deoxyguanosine; TAB-seq $=$ TETassisted bisulfite sequencing; MAPK = mitogen-activated protein kinase; CE-ESI-MS = capillary electrophoresiselectrospray ionization-mass spectrometry; DOX = doxycycline. 


\section{Concluding Remarks and Future Perspectives}

In 2009, the remarkable rebirth of an old epigenetic mark, discovered 37 years earlier [31], untangled the much-anticipated mechanism of active DNA demethylation in mammalian cells $[32,33]$. Since then, a tremendous body of research has implicated DNA hydroxymethylation in a wide variety of biological processes, from pluripotency and cell differentiation to neural system development and aging to an array of diseases, especially cancer $[21,22,24,33]$. Because smoking is a major risk factor for many types of human cancer [4,6], elucidating the role of DNA hydroxymethylation in smoking-associated carcinogenesis has the potential to translate to biomarker discovery in patient populations as well as in healthy smokers susceptible to cancer. The existing data show a highly complex and interconnected interplay between 5-hmC and TETs in transcriptional dysregulation of key genes involved in tumorigenesis and carcinogenesis, as shown in samples from cancer patients and experimental model systems $[21,33,38,114,118,119]$.

Global depletion of 5-hmC together with locus-specific gain/loss of hydroxymethylation and variation in TETs activity and function, which are highly cell-type dependent, are hallmarks of cancer, as observed in solid tumors from patients with smoking-associated malignancies and in in vitro or in vivo systems [22-24]. The detectability of these changes in early stages of carcinogenesis suggests that these alterations may serve as novel biomarkers for the early detection of smoking-associated cancers. The prognostic value of these modifications, however, has yet to be consistently confirmed in cancer patients as the disease progresses and tumor grade and stage advance.

An area of interest is the use of non- or minimally invasive surrogate tissues, which would faithfully inform the occurrence of epigenetic changes in target organs of smokingassociated cancers. In addition to conventional surrogate tissues, such as peripheral blood, oral epithelial cells, and urine $[169,212,213]$, the use of liquid biopsy to collect body fluid samples containing circulating tumor cells, circulating tumor DNA, and exosomes (i.e., extracellular vesicles filled with DNA, RNA, or proteins) in the blood have been exploited for cancer epigenetic studies $[214,215]$. These non- or minimally invasive sampling techniques may prove ideal for patient monitoring and population-based studies. So far, analysis of samples collected by these techniques has yielded both promising and inconclusive results. However, caution must be taken in interpreting these results, especially given the cell-type specificity of epigenetic changes $[24,214,216]$. This is of paramount importance when analyzing liquid biopsy specimens that contain cfDNA, cells, or exosomes that originated from various tissues that enter the blood circulation [214-216].

As we continue to investigate the role of DNA hydroxymethylation in the initiation and progression of smoking-associated cancers in patient populations, we should also expand our studies to healthy populations of smokers and nonsmokers. The latter studies, particularly with a prospective design, should facilitate identification and validation of diagnostic and prognostic biomarkers of smoking-associated cancers. With the same token, the growing population of electronic nicotine delivery system (ENDS) users, whose alternative tobacco products are known to contain toxic and carcinogenic compounds (albeit generally at substantially lower levels than tobacco cigarettes) [217-223], represents yet another important source population.

Author Contributions: A.B.: conceived the study, performed literature search, analyzed data, and wrote the manuscript. A.C.: performed literature search and co-wrote a rough draft; S.T.: performed literature search, analyzed data, and reviewed the manuscript. All authors have read and agreed to the published version of the manuscript.

Funding: This work was supported by grants from the National Cancer Institute (NCI) of the National Institutes of Health (1R21CA268197) and the University of California Tobacco-Related Disease Research Program (28IR-0058 and T31IR-1839) to A.B.

Data Availability Statement: The data presented in this review article are contained within the article. 
Conflicts of Interest: The authors declare no conflict of interest. The sponsors of the study had no role in study design, data collection, data analysis, data interpretation, writing of the report, or in the decision to submit for publication.

\begin{abstract}
Abbreviations
2D-UPLC-MS/MS, two-dimensional ultra-performance liquid chromatography with tandem mass spectrometry; 2-HG, 2-hydroxyglutarate; 5-caC, 5-carboxylcytosine; 5-fC, 5-formylcytosine; 5-hmC, 5-hydroxymethylcytosine; 5-mC, 5-methylcytosine; 8-oxodG, 8-oxo-7,8-dihydro-2'-deoxyguanosine; AD, adenomas; AFP, alpha-fetoprotein; $\alpha-\mathrm{KG}, \alpha$-ketoglutarate; ATG7, autophagy-related gene 7; AUF1, AU-rich element RNA-binding protein 1; BER, base excision repair; $C A$, carbohydrate antigen; CD44s, CD44 standard; CEA, carcinoembryonic antigen; cfDNA, cell-free DNA; CNS, central nervous system; CRC, colorectal cancer; C, cytosine; DKK, 3Dickkopf Homolog; DNMTs, DNA methyltransferases; DHHA, 4,5-dihydroxyhexanoic acid; DOX, doxycycline; EGFR, epidermal growth factor receptor; ENDS, electronic nicotine delivery systems; $\mathrm{FH}$, fumarate hydratase; GO, gene ontology; HIF, hypoxia-inducible factor; IBD, inflammatory bowel disease; IHC, immunohistochemistry; IARC, International Agency for Research on Cancer; IDH, isocitrate dehydrogenase; gDNA, genomic DNA; KEGG, Kyoto Encyclopedia of Genes and Genomes; LUSC, lung squamous cell carcinoma; MAPK, mitogen-activated protein kinase; miRNA, microRNA; NSCLC, non-small-cell lung cancer; NSE, neuron-specific enolase; oxBS-seq, oxidative bisulfite sequencing; OGG1, 8-oxoguanine DNA glycosylase; PRC2, polycomb repressive complex 2; ROS, reactive oxygen species; RT-qPCR, reverse-transcription quantitative polymerase chain reaction; $\mathrm{SDH}$, succinate dehydrogenase; shRNA, small/short hairpin RNA; TAB-seq, TET-assisted bisulfite sequencing; TDG, thymine DNA glycosylase; TET, ten-eleven translocation; TF, transcription factor; TSS, transcription start site; UHRF1, ubiquitin-like with PHD and ring finger domains 1; USP28, ubiquitin specific peptidase 28; XIST, $\mathrm{X}$-inactive specific transcript.
\end{abstract}

\title{
References
}

1. American Cancer Society (ACS). Cancer Facts \& Figures 2020; American Cancer Society: Atlanta, GA, USA, 2020.

2. Siegel, R.L.; Miller, K.D.; Jemal, A. Cancer statistics, 2020. CA Cancer J. Clin. 2020, 70, 7-30. [CrossRef]

3. Jemal, A.; Torre, L.; Soerjomataram, I.; Bray, F. The Cancer Atlas, 3rd ed.; American Cancer Society: Atlanta, GA, USA, 2019.

4. The US Surgeon General. The Health Consequences of Smoking - 50 Years of Progress: A Report of the Surgeon General; US Department of Health and Human Services, Centers for Disease Control and Prevention, National Center for Chronic Disease Prevention and Health Promotion, Office on Smoking and Health: Cincinnati, OH, USA, 2014.

5. World Health Organization (WHO). WHO Report on the Global Tobacco Epidemic 2019: Offer Help to Quit Tobacco Use; World Health Organization: Geneva, Switzerland, 2019.

6. Interntional Agency for Research on Cancer (IARC). IARC Monographs on the Evaluation of Carcinogenic Risks to Humans: Tobacco Smoke and Involuntary Smoking; Interntional Agency for Research on Cancer: Lyon, France, 2004.

7. Reitsma, M.B.; Flor, L.S.; Mullany, E.C.; Gupta, V.; Hay, S.I.; Gakidou, E. Spatial, temporal, and demographic patterns in prevalence of smoking tobacco use and initiation among young people in 204 countries and territories, 1990-2019. Lancet Public Health 2021, 6, e472-e481. [CrossRef]

8. Collaborators, G.T. Spatial, temporal, and demographic patterns in prevalence of smoking tobacco use and attributable disease burden in 204 countries and territories, 1990-2019: A systematic analysis from the Global Burden of Disease Study 2019. Lancet 2021, 397, 2337-2360. [CrossRef]

9. You, J.S.; Jones, P.A. Cancer genetics and epigenetics: Two sides of the same coin? Cancer Cell 2012, 22, 9-20. [CrossRef] [PubMed]

10. Baylin, S.B.; Jones, P.A. Epigenetic Determinants of Cancer. Cold Spring Harb. Perspect. Biol. 2016, 8, a019505. [CrossRef] [PubMed]

11. Feinberg, A.P.; Koldobskiy, M.A.; Göndör, A. Epigenetic modulators, modifiers and mediators in cancer aetiology and progression. Nat. Rev. Genet. 2016, 17, 284-299. [CrossRef]

12. Alexandrov, L.B.; Kim, J.; Haradhvala, N.J.; Huang, M.N.; Tian Ng, A.W.; Wu, Y.; Boot, A.; Covington, K.R.; Gordenin, D.A.; Bergstrom, E.N.; et al. The repertoire of mutational signatures in human cancer. Nature 2020, 578, 94-101. [CrossRef]

13. Bayik, D.; Lathia, J.D. Cancer stem cell-immune cell crosstalk in tumour progression. Nat. Rev. Cancer 2021, 21, 526-536. [CrossRef]

14. Hiam-Galvez, K.J.; Allen, B.M.; Spitzer, M.H. Systemic immunity in cancer. Nat. Rev. Cancer 2021, 21, 345-359. [CrossRef]

15. Besaratinia, A.; Tommasi, S. Epigenetics of human melanoma: Promises and challenges. J. Mol. Cell Biol. 2014, 6, 356-367. [CrossRef]

16. Berdasco, M.; Esteller, M. Clinical epigenetics: Seizing opportunities for translation. Nat. Rev. Genet. 2019, 20, 109-127. [CrossRef] [PubMed] 
17. Esteller, M.; Pandolfi, P.P. The Epitranscriptome of Noncoding RNAs in Cancer. Cancer Discov. 2017, 7, 359-368. [CrossRef] [PubMed]

18. Jones, P.A.; Issa, J.P.; Baylin, S. Targeting the cancer epigenome for therapy. Nat. Rev. Genet. 2016, 17, 630-641. [CrossRef] [PubMed]

19. Martinez-Useros, J.; Martin-Galan, M.; Florez-Cespedes, M.; Garcia-Foncillas, J. Epigenetics of Most Aggressive Solid Tumors: Pathways, Targets and Treatments. Cancers 2021, 13, 3209. [CrossRef]

20. Rodger, E.J.; Chatterjee, A.; Morison, I.M. 5-hydroxymethylcytosine: A potential therapeutic target in cancer. Epigenomics 2014, 6, 503-514. [CrossRef]

21. Wu, X.; Zhang, Y. TET-Mediated active DNA demethylation: Mechanism, function and beyond. Nat. Rev. Genet. 2017, 18, 517-534. [CrossRef]

22. Thomson, J.P.; Meehan, R.R. The application of genome-wide 5-hydroxymethylcytosine studies in cancer research. Epigenomics 2017, 9, 77-91. [CrossRef]

23. Jeschke, J.; Collignon, E.; Fuks, F. Portraits of TET-mediated DNA hydroxymethylation in cancer. Curr. Opin. Genet. Dev. 2016, 36, 16-26. [CrossRef]

24. $\mathrm{Xu}, \mathrm{T} . ; \mathrm{Gao}, \mathrm{H}$. Hydroxymethylation and tumors: Can 5-hydroxymethylation be used as a marker for tumor diagnosis and treatment? Hum. Genom. 2020, 14, 15. [CrossRef]

25. Koch, A.; Joosten, S.C.; Feng, Z.; de Ruijter, T.C.; Draht, M.X.; Melotte, V.; Smits, K.M.; Veeck, J.; Herman, J.G.; Van Neste, L.; et al. Analysis of DNA methylation in cancer: Location revisited. Nat. Rev. Clin. Oncol. 2018, 15, 459-466. [CrossRef]

26. Michalak, E.M.; Burr, M.L.; Bannister, A.J.; Dawson, M.A. The roles of DNA, RNA and histone methylation in ageing and cancer. Nat. Rev. Mol. Cell Biol. 2019, 20, 573-589. [CrossRef]

27. Greenberg, M.V.C.; Bourc'his, D. The diverse roles of DNA methylation in mammalian development and disease. Nat. Rev. Mol. Cell Biol. 2019, 20, 590-607. [CrossRef] [PubMed]

28. Martire, S.; Banaszynski, L.A. The roles of histone variants in fine-tuning chromatin organization and function. Nat. Rev. Mol. Cell Biol. 2020, 21, 522-541. [CrossRef] [PubMed]

29. Zhang, W.; Qu, J.; Liu, G.H.; Belmonte, J.C.I. The ageing epigenome and its rejuvenation. Nat. Rev. Mol. Cell Biol. 2020, 21, 137-150. [CrossRef]

30. Blanco, E.; González-Ramírez, M.; Alcaine-Colet, A.; Aranda, S.; Di Croce, L. The Bivalent Genome: Characterization, Structure, and Regulation. Trends Genet. TIG 2020, 36, 118-131. [CrossRef]

31. Penn, N.W.; Suwalski, R.; O'Riley, C.; Bojanowski, K.; Yura, R. The presence of 5-hydroxymethylcytosine in animal deoxyribonucleic acid. Biochem. J. 1972, 126, 781-790. [CrossRef]

32. Wang, J.; Tang, J.; Lai, M.; Zhang, H. 5-Hydroxymethylcytosine and disease. Mutat. Res. Rev. Mutat. Res. 2014, 762, 167-175. [CrossRef] [PubMed]

33. Szyf, M. The elusive role of 5'-hydroxymethylcytosine. Epigenomics 2016, 8, 1539-1551. [CrossRef]

34. Kriaucionis, S.; Heintz, N. The nuclear DNA base 5-hydroxymethylcytosine is present in Purkinje neurons and the brain. Science 2009, 324, 929-930. [CrossRef] [PubMed]

35. Tahiliani, M.; Koh, K.P.; Shen, Y.; Pastor, W.A.; Bandukwala, H.; Brudno, Y.; Agarwal, S.; Iyer, L.M.; Liu, D.R.; Aravind, L.; et al. Conversion of 5-methylcytosine to 5-hydroxymethylcytosine in mammalian DNA by MLL partner TET1. Science 2009, 324, 930-935. [CrossRef] [PubMed]

36. Münzel, M.; Globisch, D.; Brückl, T.; Wagner, M.; Welzmiller, V.; Michalakis, S.; Müller, M.; Biel, M.; Carell, T. Quantification of the sixth DNA base hydroxymethylcytosine in the brain. Angew. Chem. Int. Ed. 2010, 49, 5375-5377. [CrossRef] [PubMed]

37. Lister, R.; Ecker, J.R. Finding the fifth base: Genome-wide sequencing of cytosine methylation. Genome Res. 2009, 19, 959-966. [CrossRef] [PubMed]

38. Shi, D.Q.; Ali, I.; Tang, J.; Yang, W.C. New Insights into 5hmC DNA Modification: Generation, Distribution and Function. Front. Genet. 2017, 8, 100. [CrossRef] [PubMed]

39. He, Y.F.; Li, B.Z.; Li, Z.; Liu, P.; Wang, Y.; Tang, Q.; Ding, J.; Jia, Y.; Chen, Z.; Li, L.; et al. Tet-mediated formation of 5carboxylcytosine and its excision by TDG in mammalian DNA. Science 2011, 333, 1303-1307. [CrossRef] [PubMed]

40. Maiti, A.; Drohat, A.C. Thymine DNA glycosylase can rapidly excise 5-formylcytosine and 5-carboxylcytosine: Potential implications for active demethylation of CpG sites. J. Biol. Chem. 2011, 286, 35334-35338. [CrossRef]

41. Hashimoto, H.; Hong, S.; Bhagwat, A.S.; Zhang, X.; Cheng, X. Excision of 5-hydroxymethyluracil and 5-carboxylcytosine by the thymine DNA glycosylase domain: Its structural basis and implications for active DNA demethylation. Nucleic Acids Res. 2012, 40, 10203-10214. [CrossRef]

42. Kohli, R.M.; Zhang, Y. TET enzymes, TDG and the dynamics of DNA demethylation. Nature 2013, 502, 472-479. [CrossRef]

43. Lyko, F. The DNA methyltransferase family: A versatile toolkit for epigenetic regulation. Nat. Rev. Genet. 2018, 19, 81-92. [CrossRef]

44. Bostick, M.; Kim, J.K.; Estève, P.O.; Clark, A.; Pradhan, S.; Jacobsen, S.E. UHRF1 plays a role in maintaining DNA methylation in mammalian cells. Science 2007, 317, 1760-1764. [CrossRef]

45. Sharif, J.; Muto, M.; Takebayashi, S.; Suetake, I.; Iwamatsu, A.; Endo, T.A.; Shinga, J.; Mizutani-Koseki, Y.; Toyoda, T.; Okamura, K.; et al. The SRA protein Np95 mediates epigenetic inheritance by recruiting Dnmt1 to methylated DNA. Nature 2007, 450, 908-912. [CrossRef] 
46. Hermann, A.; Goyal, R.; Jeltsch, A. The Dnmt1 DNA-(cytosine-C5)-methyltransferase methylates DNA processively with high preference for hemimethylated target sites. J. Biol. Chem. 2004, 279, 48350-48359. [CrossRef] [PubMed]

47. Hashimoto, H.; Liu, Y.; Upadhyay, A.K.; Chang, Y.; Howerton, S.B.; Vertino, P.M.; Zhang, X.; Cheng, X. Recognition and potential mechanisms for replication and erasure of cytosine hydroxymethylation. Nucleic Acids Res. 2012, 40, 4841-4849. [CrossRef] [PubMed]

48. Otani, J.; Kimura, H.; Sharif, J.; Endo, T.A.; Mishima, Y.; Kawakami, T.; Koseki, H.; Shirakawa, M.; Suetake, I.; Tajima, S. Cell cycle-dependent turnover of 5-hydroxymethyl cytosine in mouse embryonic stem cells. PLoS ONE 2013, 8, e82961. [CrossRef]

49. Valinluck, V.; Sowers, L.C. Endogenous cytosine damage products alter the site selectivity of human DNA maintenance methyltransferase DNMT1. Cancer Res. 2007, 67, 946-950. [CrossRef] [PubMed]

50. Ji, D.; Lin, K.; Song, J.; Wang, Y. Effects of Tet-induced oxidation products of 5-methylcytosine on Dnmt1- and DNMT3a-mediated cytosine methylation. Mol. Biosyst. 2014, 10, 1749-1752. [CrossRef]

51. Chen, C.C.; Wang, K.Y.; Shen, C.K. The mammalian de novo DNA methyltransferases DNMT3A and DNMT3B are also DNA 5-hydroxymethylcytosine dehydroxymethylases. J. Biol. Chem. 2012, 287, 33116-33121. [CrossRef] [PubMed]

52. Van der Wijst, M.G.; Venkiteswaran, M.; Chen, H.; Xu, G.L.; Plösch, T.; Rots, M.G. Local chromatin microenvironment determines DNMT activity: From DNA methyltransferase to DNA demethylase or DNA dehydroxymethylase. Epigenetics $\mathbf{2 0 1 5}$ 10, 671-676. [CrossRef]

53. Branco, M.R.; Ficz, G.; Reik, W. Uncovering the role of 5-hydroxymethylcytosine in the epigenome. Nat. Rev. Genet. 2011, 13, 7-13. [CrossRef]

54. Losman, J.A.; Kaelin, W.G., Jr. What a difference a hydroxyl makes: Mutant IDH, (R)-2-hydroxyglutarate, and cancer. Genes Dev. 2013, 27, 836-852. [CrossRef]

55. Prescott, A.G.; Lloyd, M.D. The iron(II) and 2-oxoacid-dependent dioxygenases and their role in metabolism. Nat. Prod. Rep. 2000, 17, 367-383. [CrossRef]

56. Hausinger, R.P. FeII/alpha-ketoglutarate-dependent hydroxylases and related enzymes. Crit. Rev. Biochem. Mol. Biol. 2004, 39, 21-68. [CrossRef] [PubMed]

57. Inoue, A.; Shen, L.; Dai, Q.; He, C.; Zhang, Y. Generation and replication-dependent dilution of 5fC and 5caC during mouse preimplantation development. Cell Res. 2011, 21, 1670-1676. [CrossRef] [PubMed]

58. Ito, S.; Shen, L.; Dai, Q.; Wu, S.C.; Collins, L.B.; Swenberg, J.A.; He, C.; Zhang, Y. Tet proteins can convert 5-methylcytosine to 5-formylcytosine and 5-carboxylcytosine. Science 2011, 333, 1300-1303. [CrossRef] [PubMed]

59. Wu, H.; Zhang, Y. Reversing DNA methylation: Mechanisms, genomics, and biological functions. Cell 2014, 156, 45-68. [CrossRef]

60. Weber, A.R.; Krawczyk, C.; Robertson, A.B.; Kuśnierczyk, A.; Vågbø, C.B.; Schuermann, D.; Klungland, A.; Schär, P. Biochemical reconstitution of TET1-TDG-BER-dependent active DNA demethylation reveals a highly coordinated mechanism. Nat. Commun. 2016, 7, 10806. [CrossRef]

61. Kroeze, L.I.; van der Reijden, B.A.; Jansen, J.H. 5-Hydroxymethylcytosine: An epigenetic mark frequently deregulated in cancer. Biochim. Biophys. Acta 2015, 1855, 144-154. [CrossRef]

62. Lu, X.; Zhao, B.S.; He, C. TET family proteins: Oxidation activity, interacting molecules, and functions in diseases. Chem. Rev. 2015, 115, 2225-2239. [CrossRef]

63. Zhao, B.; Yang, Y.; Wang, X.; Chong, Z.; Yin, R.; Song, S.H.; Zhao, C.; Li, C.; Huang, H.; Sun, B.F.; et al. Redox-Active quinones induces genome-wide DNA methylation changes by an iron-mediated and Tet-dependent mechanism. Nucleic Acids Res. 2014, 42, 1593-1605. [CrossRef] [PubMed]

64. Laukka, T.; Mariani, C.J.; Ihantola, T.; Cao, J.Z.; Hokkanen, J.; Kaelin, W.G., Jr.; Godley, L.A.; Koivunen, P. Fumarate and Succinate Regulate Expression of Hypoxia-inducible Genes via TET Enzymes. J. Biol. Chem. 2016, 291, 4256-4265. [CrossRef]

65. Blaschke, K.; Ebata, K.T.; Karimi, M.M.; Zepeda-Martínez, J.A.; Goyal, P.; Mahapatra, S.; Tam, A.; Laird, D.J.; Hirst, M.; Rao, A.; et al. Vitamin C induces Tet-dependent DNA demethylation and a blastocyst-like state in ES cells. Nature 2013, 500, 222-226. [CrossRef]

66. Minor, E.A.; Court, B.L.; Young, J.I.; Wang, G. Ascorbate induces ten-eleven translocation (Tet) methylcytosine dioxygenasemediated generation of 5-hydroxymethylcytosine. J. Biol. Chem. 2013, 288, 13669-13674. [CrossRef] [PubMed]

67. Yin, R.; Mao, S.Q.; Zhao, B.; Chong, Z.; Yang, Y.; Zhao, C.; Zhang, D.; Huang, H.; Gao, J.; Li, Z.; et al. Ascorbic acid enhances Tetmediated 5-methylcytosine oxidation and promotes DNA demethylation in mammals. J. Am. Chem. Soc. 2013, 135, 10396-10403. [CrossRef] [PubMed]

68. Xiao, M.; Yang, H.; Xu, W.; Ma, S.; Lin, H.; Zhu, H.; Liu, L.; Liu, Y.; Yang, C.; Xu, Y.; et al. Inhibition of $\alpha$-KG-dependent histone and DNA demethylases by fumarate and succinate that are accumulated in mutations of FH and SDH tumor suppressors. Genes Dev. 2012, 26, 1326-1338. [CrossRef] [PubMed]

69. Liu, Y.; Jiang, W.; Liu, J.; Zhao, S.; Xiong, J.; Mao, Y.; Wang, Y. IDH1 mutations inhibit multiple $\alpha$-ketoglutarate-dependent dioxygenase activities in astroglioma. J. Neurooncol. 2012, 109, 253-260. [CrossRef] [PubMed]

70. Ward, P.S.; Patel, J.; Wise, D.R.; Abdel-Wahab, O.; Bennett, B.D.; Coller, H.A.; Cross, J.R.; Fantin, V.R.; Hedvat, C.V.; Perl, A.E.; et al. The common feature of leukemia-associated IDH1 and IDH2 mutations is a neomorphic enzyme activity converting alphaketoglutarate to 2-hydroxyglutarate. Cancer Cell 2010, 17, 225-234. [CrossRef]

71. Xu, W.; Yang, H.; Liu, Y.; Yang, Y.; Wang, P.; Kim, S.H.; Ito, S.; Yang, C.; Wang, P.; Xiao, M.T.; et al. Oncometabolite 2hydroxyglutarate is a competitive inhibitor of $\alpha$-ketoglutarate-dependent dioxygenases. Cancer Cell 2011, 19, 17-30. [CrossRef] 
72. Lian, C.G.; Xu, Y.; Ceol, C.; Wu, F.; Larson, A.; Dresser, K.; Xu, W.; Tan, L.; Hu, Y.; Zhan, Q.; et al. Loss of 5-hydroxymethylcytosine is an epigenetic hallmark of melanoma. Cell 2012, 150, 1135-1146. [CrossRef]

73. Mason, E.F.; Hornick, J.L. Succinate dehydrogenase deficiency is associated with decreased 5-hydroxymethylcytosine production in gastrointestinal stromal tumors: Implications for mechanisms of tumorigenesis. Mod. Pathol. 2013, 26, 1492-1497. [CrossRef]

74. Castro-Vega, L.J.; Buffet, A.; De Cubas, A.A.; Cascón, A.; Menara, M.; Khalifa, E.; Amar, L.; Azriel, S.; Bourdeau, I.; Chabre, O.; et al. Germline mutations in FH confer predisposition to malignant pheochromocytomas and paragangliomas. Hum. Mol. Genet. 2014, 23, 2440-2446. [CrossRef]

75. Yang, H.; Liu, Y.; Bai, F.; Zhang, J.Y.; Ma, S.H.; Liu, J.; Xu, Z.D.; Zhu, H.G.; Ling, Z.Q.; Ye, D.; et al. Tumor development is associated with decrease of TET gene expression and 5-methylcytosine hydroxylation. Oncogene 2013, 32, 663-669. [CrossRef]

76. Pollard, P.J.; Brière, J.J.; Alam, N.A.; Barwell, J.; Barclay, E.; Wortham, N.C.; Hunt, T.; Mitchell, M.; Olpin, S.; Moat, S.J.; et al. Accumulation of Krebs cycle intermediates and over-expression of HIF1alpha in tumours which result from germline FH and SDH mutations. Hum. Mol. Genet. 2005, 14, 2231-2239. [CrossRef]

77. Lv, X.; Jiang, H.; Liu, Y.; Lei, X.; Jiao, J. MicroRNA-15b promotes neurogenesis and inhibits neural progenitor proliferation by directly repressing TET3 during early neocortical development. EMBO Rep. 2014, 15, 1305-1314. [CrossRef]

78. Song, S.J.; Ito, K.; Ala, U.; Kats, L.; Webster, K.; Sun, S.M.; Jongen-Lavrencic, M.; Manova-Todorova, K.; Teruya-Feldstein, J.; Avigan, D.E.; et al. The oncogenic microRNA miR-22 targets the TET2 tumor suppressor to promote hematopoietic stem cell self-renewal and transformation. Cell Stem Cell 2013, 13, 87-101. [CrossRef]

79. Song, S.J.; Poliseno, L.; Song, M.S.; Ala, U.; Webster, K.; Ng, C.; Beringer, G.; Brikbak, N.J.; Yuan, X.; Cantley, L.C.; et al. MicroRNA-Antagonism regulates breast cancer stemness and metastasis via TET-family-dependent chromatin remodeling. Cell 2013, 154, 311-324. [CrossRef]

80. Fu, X.; Jin, L.; Wang, X.; Luo, A.; Hu, J.; Zheng, X.; Tsark, W.M.; Riggs, A.D.; Ku, H.T.; Huang, W. MicroRNA-26a targets ten eleven translocation enzymes and is regulated during pancreatic cell differentiation. Proc. Natl. Acad. Sci. USA 2013, 110, 17892-17897. [CrossRef]

81. Cheng, J.; Guo, S.; Chen, S.; Mastriano, S.J.; Liu, C.; D’Alessio, A.C.; Hysolli, E.; Guo, Y.; Yao, H.; Megyola, C.M.; et al. An extensive network of TET2-targeting MicroRNAs regulates malignant hematopoiesis. Cell Rep. 2013, 5, 471-481. [CrossRef]

82. Morita, S.; Horii, T.; Kimura, M.; Ochiya, T.; Tajima, S.; Hatada, I. miR-29 represses the activities of DNA methyltransferases and DNA demethylases. Int. J. Mol. Sci. 2013, 14, 14647-14658. [CrossRef]

83. Sengupta, S.; den Boon, J.A.; Chen, I.H.; Newton, M.A.; Stanhope, S.A.; Cheng, Y.J.; Chen, C.J.; Hildesheim, A.; Sugden, B.; Ahlquist, P. MicroRNA 29c is down-regulated in nasopharyngeal carcinomas, up-regulating mRNAs encoding extracellular matrix proteins. Proc. Natl. Acad. Sci. USA 2008, 105, 5874-5878. [CrossRef]

84. Zhang, P.; Huang, B.; Xu, X.; Sessa, W.C. Ten-Eleven translocation (Tet) and thymine DNA glycosylase (TDG), components of the demethylation pathway, are direct targets of miRNA-29a. Biochem. Biophys. Res. Commun. 2013, 437, 368-373. [CrossRef]

85. Takayama, K.; Misawa, A.; Suzuki, T.; Takagi, K.; Hayashizaki, Y.; Fujimura, T.; Homma, Y.; Takahashi, S.; Urano, T.; Inoue, $\mathrm{S}$. TET2 repression by androgen hormone regulates global hydroxymethylation status and prostate cancer progression. Nat. Commun. 2015, 6, 8219. [CrossRef]

86. Chuang, K.H.; Whitney-Miller, C.L.; Chu, C.Y.; Zhou, Z.; Dokus, M.K.; Schmit, S.; Barry, C.T. MicroRNA-494 is a master epigenetic regulator of multiple invasion-suppressor microRNAs by targeting ten eleven translocation 1 in invasive human hepatocellular carcinoma tumors. Hepatology 2015, 62, 466-480. [CrossRef]

87. Fidalgo, M.; Huang, X.; Guallar, D.; Sanchez-Priego, C.; Valdes, V.J.; Saunders, A.; Ding, J.; Wu, W.S.; Clavel, C.; Wang, J. Zfp281 Coordinates Opposing Functions of Tet1 and Tet2 in Pluripotent States. Cell Stem Cell 2016, 19, 355-369. [CrossRef]

88. Jacobsen, A.; Silber, J.; Harinath, G.; Huse, J.T.; Schultz, N.; Sander, C. Analysis of microRNA-target interactions across diverse cancer types. Nat. Struct. Mol. Biol. 2013, 20, 1325-1332. [CrossRef]

89. Nakagawa, T.; Lv, L.; Nakagawa, M.; Yu, Y.; Yu, C.; D'Alessio, A.C.; Nakayama, K.; Fan, H.Y.; Chen, X.; Xiong, Y. CRL4(VprBP) E3 ligase promotes monoubiquitylation and chromatin binding of TET dioxygenases. Mol. Cell 2015, 57, 247-260. [CrossRef]

90. Zhang, Y.W.; Wang, Z.; Xie, W.; Cai, Y.; Xia, L.; Easwaran, H.; Luo, J.; Yen, R.C.; Li, Y.; Baylin, S.B. Acetylation Enhances TET2 Function in Protecting against Abnormal DNA Methylation during Oxidative Stress. Mol. Cell 2017, 65, 323-335. [CrossRef]

91. Jiang, D.; Zhang, Y.; Hart, R.P.; Chen, J.; Herrup, K.; Li, J. Alteration in 5-hydroxymethylcytosine-mediated epigenetic regulation leads to Purkinje cell vulnerability in ATM deficiency. Brain 2015, 138, 3520-3536. [CrossRef]

92. Shi, F.T.; Kim, H.; Lu, W.; He, Q.; Liu, D.; Goodell, M.A.; Wan, M.; Songyang, Z. Ten-Eleven translocation 1 (Tet1) is regulated by O-linked N-acetylglucosamine transferase (Ogt) for target gene repression in mouse embryonic stem cells. J. Biol. Chem. 2013, 288, 20776-20784. [CrossRef]

93. Zhang, Q.; Liu, X.; Gao, W.; Li, P.; Hou, J.; Li, J.; Wong, J. Differential regulation of the ten-eleven translocation (TET) family of dioxygenases by O-linked $\beta-\mathrm{N}$-acetylglucosamine transferase (OGT). J. Biol. Chem. 2014, 289, 5986-5996. [CrossRef]

94. Bauer, C.; Göbel, K.; Nagaraj, N.; Colantuoni, C.; Wang, M.; Müller, U.; Kremmer, E.; Rottach, A.; Leonhardt, H. Phosphorylation of TET proteins is regulated via O-GlcNAcylation by the O-linked $\mathrm{N}$-acetylglucosamine transferase (OGT). J. Biol. Chem. 2015, 290, 4801-4812. [CrossRef]

95. Ciccarone, F.; Valentini, E.; Zampieri, M.; Caiafa, P. 5mC-hydroxylase activity is influenced by the PARylation of TET1 enzyme. Oncotarget 2015, 6, 24333-24347. [CrossRef] 
96. Ko, M.; An, J.; Bandukwala, H.S.; Chavez, L.; Aijö, T.; Pastor, W.A.; Segal, M.F.; Li, H.; Koh, K.P.; Lähdesmäki, H.; et al. Modulation of TET2 expression and 5-methylcytosine oxidation by the CXXC domain protein IDAX. Nature 2013, 497, 122-126. [CrossRef]

97. Wang, Y.; Zhang, Y. Regulation of TET protein stability by calpains. Cell Rep. 2014, 6, 278-284. [CrossRef]

98. Pfaffeneder, T.; Hackner, B.; Truss, M.; Münzel, M.; Müller, M.; Deiml, C.A.; Hagemeier, C.; Carell, T. The discovery of 5-formylcytosine in embryonic stem cell DNA. Angew. Chem. Int. Ed. Engl. 2011, 50, 7008-7012. [CrossRef]

99. Hu, L.; Lu, J.; Cheng, J.; Rao, Q.; Li, Z.; Hou, H.; Lou, Z.; Zhang, L.; Li, W.; Gong, W.; et al. Structural insight into substrate preference for TET-mediated oxidation. Nature 2015, 527, 118-122. [CrossRef]

100. Klungland, A.; Robertson, A.B. Oxidized C5-methyl cytosine bases in DNA: 5-Hydroxymethylcytosine; 5-formylcytosine; and 5-carboxycytosine. Free Radic. Biol. Med. 2017, 107, 62-68. [CrossRef]

101. Globisch, D.; Münzel, M.; Müller, M.; Michalakis, S.; Wagner, M.; Koch, S.; Brückl, T.; Biel, M.; Carell, T. Tissue distribution of 5-hydroxymethylcytosine and search for active demethylation intermediates. PLoS ONE 2010, 5, e15367. [CrossRef]

102. Song, C.X.; Diao, J.; Brunger, A.T.; Quake, S.R. Simultaneous single-molecule epigenetic imaging of DNA methylation and hydroxymethylation. Proc. Natl. Acad. Sci. USA 2016, 113, 4338-4343. [CrossRef]

103. Herrup, K.; Yang, Y. Cell cycle regulation in the postmitotic neuron: Oxymoron or new biology? Nat. Rev. Neurosci. 2007, 8 , 368-378. [CrossRef]

104. Anda, F.C.; Madabhushi, R.; Rei, D.; Meng, J.; Gräff, J.; Durak, O.; Meletis, K.; Richter, M.; Schwanke, B.; Mungenast, A.; et al. Cortical neurons gradually attain a post-mitotic state. Cell Res. 2016, 26, 1033-1047. [CrossRef]

105. Nestor, C.E.; Ottaviano, R.; Reddington, J.; Sproul, D.; Reinhardt, D.; Dunican, D.; Katz, E.; Dixon, J.M.; Harrison, D.J.; Meehan, R.R. Tissue type is a major modifier of the 5-hydroxymethylcytosine content of human genes. Genome Res. 2012, 22, 467-477. [CrossRef]

106. Tan, L.; Xiong, L.; Xu, W.; Wu, F.; Huang, N.; Xu, Y.; Kong, L.; Zheng, L.; Schwartz, L.; Shi, Y.; et al. Genome-Wide comparison of DNA hydroxymethylation in mouse embryonic stem cells and neural progenitor cells by a new comparative hMeDIP-seq method. Nucleic Acids Res. 2013, 41, e84. [CrossRef] [PubMed]

107. Ito, S.; D'Alessio, A.C.; Taranova, O.V.; Hong, K.; Sowers, L.C.; Zhang, Y. Role of Tet proteins in 5mC to 5hmC conversion, ES-cell self-renewal and inner cell mass specification. Nature 2010, 466, 1129-1133. [CrossRef] [PubMed]

108. Bachman, M.; Uribe-Lewis, S.; Yang, X.; Williams, M.; Murrell, A.; Balasubramanian, S. 5-Hydroxymethylcytosine is a predominantly stable DNA modification. Nat. Chem. 2014, 6, 1049-1055. [CrossRef] [PubMed]

109. Bhutani, N.; Burns, D.M.; Blau, H.M. DNA demethylation dynamics. Cell 2011, 146, 866-872. [CrossRef] [PubMed]

110. Shen, L.; Zhang, Y. 5-Hydroxymethylcytosine: Generation, fate, and genomic distribution. Curr. Opin. Cell Biol. 2013, 25, 289-296. [CrossRef]

111. Moen, E.L.; Mariani, C.J.; Zullow, H.; Jeff-Eke, M.; Litwin, E.; Nikitas, J.N.; Godley, L.A. New themes in the biological functions of 5-methylcytosine and 5-hydroxymethylcytosine. Immunol. Rev. 2015, 263, 36-49. [CrossRef]

112. Ficz, G.; Branco, M.R.; Seisenberger, S.; Santos, F.; Krueger, F.; Hore, T.A.; Marques, C.J.; Andrews, S.; Reik, W. Dynamic regulation of 5-hydroxymethylcytosine in mouse ES cells and during differentiation. Nature 2011, 473, 398-402. [CrossRef]

113. Wu, H.; D'Alessio, A.C.; Ito, S.; Wang, Z.; Cui, K.; Zhao, K.; Sun, Y.E.; Zhang, Y. Genome-Wide analysis of 5-hydroxymethylcytosine distribution reveals its dual function in transcriptional regulation in mouse embryonic stem cells. Genes Dev. 2011, 25, 679-684. [CrossRef]

114. Williams, K.; Christensen, J.; Pedersen, M.T.; Johansen, J.V.; Cloos, P.A.; Rappsilber, J.; Helin, K. TET1 and hydroxymethylcytosine in transcription and DNA methylation fidelity. Nature 2011, 473, 343-348. [CrossRef]

115. Pastor, W.A.; Pape, U.J.; Huang, Y.; Henderson, H.R.; Lister, R.; Ko, M.; McLoughlin, E.M.; Brudno, Y.; Mahapatra, S.; Kapranov, P.; et al. Genome-Wide mapping of 5-hydroxymethylcytosine in embryonic stem cells. Nature 2011, 473, 394-397. [CrossRef]

116. Szulwach, K.E.; Li, X.; Li, Y.; Song, C.X.; Han, J.W.; Kim, S.; Namburi, S.; Hermetz, K.; Kim, J.J.; Rudd, M.K.; et al. Integrating 5-hydroxymethylcytosine into the epigenomic landscape of human embryonic stem cells. PLoS Genet. 2011, 7, e1002154. [CrossRef] [PubMed]

117. Kubiura, M.; Okano, M.; Kimura, H.; Kawamura, F.; Tada, M. Chromosome-Wide regulation of euchromatin-specific 5mC to $5 \mathrm{hmC}$ conversion in mouse ES cells and female human somatic cells. Chromosome Res. 2012, 20, 837-848. [CrossRef] [PubMed]

118. Shen, L.; Wu, H.; Diep, D.; Yamaguchi, S.; D'Alessio, A.C.; Fung, H.L.; Zhang, K.; Zhang, Y. Genome-Wide analysis reveals TETand TDG-dependent 5-methylcytosine oxidation dynamics. Cell 2013, 153, 692-706. [CrossRef]

119. Ichiyama, K.; Chen, T.; Wang, X.; Yan, X.; Kim, B.S.; Tanaka, S.; Ndiaye-Lobry, D.; Deng, Y.; Zou, Y.; Zheng, P.; et al. The methylcytosine dioxygenase Tet2 promotes DNA demethylation and activation of cytokine gene expression in T cells. Immunity 2015, 42, 613-626. [CrossRef]

120. Huang, Y.; Chavez, L.; Chang, X.; Wang, X.; Pastor, W.A.; Kang, J.; Zepeda-Martínez, J.A.; Pape, U.J.; Jacobsen, S.E.; Peters, B.; et al. Distinct roles of the methylcytosine oxidases Tet1 and Tet2 in mouse embryonic stem cells. Proc. Natl. Acad. Sci. USA 2014, 111, 1361-1366. [CrossRef]

121. Szulwach, K.E.; Li, X.; Li, Y.; Song, C.X.; Wu, H.; Dai, Q.; Irier, H.; Upadhyay, A.K.; Gearing, M.; Levey, A.I.; et al. 5-hmC-mediated epigenetic dynamics during postnatal neurodevelopment and aging. Nat. Neurosci. 2011, 14, 1607-1616. [CrossRef]

122. Song, C.X.; Szulwach, K.E.; Fu, Y.; Dai, Q.; Yi, C.; Li, X.; Li, Y.; Chen, C.H.; Zhang, W.; Jian, X.; et al. Selective chemical labeling reveals the genome-wide distribution of 5-hydroxymethylcytosine. Nat. Biotechnol. 2011, 29, 68-72. [CrossRef] [PubMed] 
123. Stroud, H.; Feng, S.; Morey Kinney, S.; Pradhan, S.; Jacobsen, S.E. 5-Hydroxymethylcytosine is associated with enhancers and gene bodies in human embryonic stem cells. Genome Biol. 2011, 12, R54. [CrossRef]

124. Mellén, M.; Ayata, P.; Dewell, S.; Kriaucionis, S.; Heintz, N. MeCP2 binds to 5hmC enriched within active genes and accessible chromatin in the nervous system. Cell 2012, 151, 1417-1430. [CrossRef]

125. Uribe-Lewis, S.; Stark, R.; Carroll, T.; Dunning, M.J.; Bachman, M.; Ito, Y.; Stojic, L.; Halim, S.; Vowler, S.L.; Lynch, A.G.; et al. 5-hydroxymethylcytosine marks promoters in colon that resist DNA hypermethylation in cancer. Genome Biol. 2015, 16, 69. [CrossRef]

126. Bernstein, B.E.; Mikkelsen, T.S.; Xie, X.; Kamal, M.; Huebert, D.J.; Cuff, J.; Fry, B.; Meissner, A.; Wernig, M.; Plath, K.; et al. A bivalent chromatin structure marks key developmental genes in embryonic stem cells. Cell 2006, 125, 315-326. [CrossRef] [PubMed]

127. Hammoud, S.S.; Low, D.H.; Yi, C.; Carrell, D.T.; Guccione, E.; Cairns, B.R. Chromatin and transcription transitions of mammalian adult germline stem cells and spermatogenesis. Cell Stem Cell 2014, 15, 239-253. [CrossRef]

128. Grosser, C.; Wagner, N.; Grothaus, K.; Horsthemke, B. Altering TET dioxygenase levels within physiological range affects DNA methylation dynamics of HEK293 cells. Epigenetics 2015, 10, 819-833. [CrossRef] [PubMed]

129. Kong, L.; Tan, L.; Lv, R.; Shi, Z.; Xiong, L.; Wu, F.; Rabidou, K.; Smith, M.; He, C.; Zhang, L.; et al. A primary role of TET proteins in establishment and maintenance of De Novo bivalency at CpG islands. Nucleic Acids Res. 2016, 44, 8682-8692. [CrossRef]

130. Neri, F.; Incarnato, D.; Krepelova, A.; Rapelli, S.; Pagnani, A.; Zecchina, R.; Parlato, C.; Oliviero, S. Genome-Wide analysis identifies a functional association of Tet1 and Polycomb repressive complex 2 in mouse embryonic stem cells. Genome Biol. 2013, 14, R91. [CrossRef]

131. Wu, H.; D'Alessio, A.C.; Ito, S.; Xia, K.; Wang, Z.; Cui, K.; Zhao, K.; Sun, Y.E.; Zhang, Y. Dual functions of Tet1 in transcriptional regulation in mouse embryonic stem cells. Nature 2011, 473, 389-393. [CrossRef]

132. Wang, E.T.; Sandberg, R.; Luo, S.; Khrebtukova, I.; Zhang, L.; Mayr, C.; Kingsmore, S.F.; Schroth, G.P.; Burge, C.B. Alternative isoform regulation in human tissue transcriptomes. Nature 2008, 456, 470-476. [CrossRef] [PubMed]

133. Khare, T.; Pai, S.; Koncevicius, K.; Pal, M.; Kriukiene, E.; Liutkeviciute, Z.; Irimia, M.; Jia, P.; Ptak, C.; Xia, M.; et al. 5-hmC in the brain is abundant in synaptic genes and shows differences at the exon-intron boundary. Nat. Struct. Mol. Biol. 2012, 19, 1037-1043. [CrossRef] [PubMed]

134. Nakajima, H.; Kunimoto, H. TET2 as an epigenetic master regulator for normal and malignant hematopoiesis. Cancer Sci. 2014, 105, 1093-1099. [CrossRef]

135. Rasmussen, K.D.; Helin, K. Role of TET enzymes in DNA methylation, development, and cancer. Genes Dev. 2016, 30, 733-750. [CrossRef]

136. Chiba, S. Dysregulation of TET2 in hematologic malignancies. Int. J. Hematol. 2017, 105, 17-22. [CrossRef] [PubMed]

137. Abdel-Wahab, O.; Mullally, A.; Hedvat, C.; Garcia-Manero, G.; Patel, J.; Wadleigh, M.; Malinge, S.; Yao, J.; Kilpivaara, O.; Bhat, R.; et al. Genetic characterization of TET1, TET2, and TET3 alterations in myeloid malignancies. Blood 2009, 114, 144-147. [CrossRef] [PubMed]

138. Delhommeau, F.; Dupont, S.; Della Valle, V.; James, C.; Trannoy, S.; Massé, A.; Kosmider, O.; Le Couedic, J.P.; Robert, F.; Alberdi, A.; et al. Mutation in TET2 in myeloid cancers. N. Engl. J. Med. 2009, 360, 2289-2301. [CrossRef] [PubMed]

139. Solary, E.; Bernard, O.A.; Tefferi, A.; Fuks, F.; Vainchenker, W. The Ten-Eleven Translocation-2 (TET2) gene in hematopoiesis and hematopoietic diseases. Leukemia 2014, 28, 485-496. [CrossRef]

140. Koivunen, P.; Laukka, T. The TET enzymes. Cell Mol. Life Sci. 2018, 75, 1339-1348. [CrossRef]

141. Gu, T.P.; Guo, F.; Yang, H.; Wu, H.P.; Xu, G.F.; Liu, W.; Xie, Z.G.; Shi, L.; He, X.; Jin, S.G.; et al. The role of Tet3 DNA dioxygenase in epigenetic reprogramming by oocytes. Nature 2011, 477, 606-610. [CrossRef]

142. Han, J.A.; An, J.; Ko, M. Functions of TET Proteins in Hematopoietic Transformation. Mol. Cells 2015, 38, 925-935. [CrossRef]

143. Bowman, R.L.; Levine, R.L. TET2 in Normal and Malignant Hematopoiesis. Cold Spring Harb. Perspect. Med. 2017, 7, a026518. [CrossRef]

144. An, J.; Rao, A.; Ko, M. TET family dioxygenases and DNA demethylation in stem cells and cancers. Exp. Mol. Med. 2017, 49, e323. [CrossRef]

145. Feng, Y.; Li, X.; Cassady, K.; Zou, Z.; Zhang, X. TET2 Function in Hematopoietic Malignancies, Immune Regulation, and DNA Repair. Front. Oncol. 2019, 9, 210. [CrossRef]

146. Li, W.; Xu, L. Epigenetic Function of TET Family, 5-Methylcytosine, and 5-Hydroxymethylcytosine in Hematologic Malignancies. Oncol. Res. Treat. 2019, 42, 309-318. [CrossRef] [PubMed]

147. Figueroa, M.E.; Abdel-Wahab, O.; Lu, C.; Ward, P.S.; Patel, J.; Shih, A.; Li, Y.; Bhagwat, N.; Vasanthakumar, A.; Fernandez, H.F.; et al. Leukemic IDH1 and IDH2 mutations result in a hypermethylation phenotype, disrupt TET2 function, and impair hematopoietic differentiation. Cancer Cell 2010, 18, 553-567. [CrossRef] [PubMed]

148. Waitkus, M.S.; Diplas, B.H.; Yan, H. Biological Role and Therapeutic Potential of IDH Mutations in Cancer. Cancer Cell 2018, 34, 186-195. [CrossRef] [PubMed]

149. Pirozzi, C.J.; Yan, H. The implications of IDH mutations for cancer development and therapy. Nat. Rev. Clin. Oncol. 2021, 18, 645-661. [CrossRef]

150. Dang, L.; White, D.W.; Gross, S.; Bennett, B.D.; Bittinger, M.A.; Driggers, E.M.; Fantin, V.R.; Jang, H.G.; Jin, S.; Keenan, M.C.; et al. Cancer-Associated IDH1 mutations produce 2-hydroxyglutarate. Nature 2009, 462, 739-744. [CrossRef] 
151. Yen, K.E.; Bittinger, M.A.; Su, S.M.; Fantin, V.R. Cancer-Associated IDH mutations: Biomarker and therapeutic opportunities. Oncogene 2010, 29, 6409-6417. [CrossRef]

152. Chang, S.; Yim, S.; Park, H. The cancer driver genes IDH1/2, JARID1C/KDM5C, and UTX/ KDM6A: Crosstalk between histone demethylation and hypoxic reprogramming in cancer metabolism. Exp. Mol. Med. 2019, 51, 1-17. [CrossRef]

153. Chia, N.; Wang, L.; Lu, X.; Senut, M.C.; Brenner, C.; Ruden, D.M. Hypothesis: Environmental regulation of 5-hydroxymethylcytosine by oxidative stress. Epigenetics 2011, 6, 853-856. [CrossRef]

154. Dziaman, T.; Gackowski, D.; Guz, J.; Linowiecka, K.; Bodnar, M.; Starczak, M.; Zarakowska, E.; Modrzejewska, M.; Szpila, A.; Szpotan, J.; et al. Characteristic profiles of DNA epigenetic modifications in colon cancer and its predisposing conditions-benign adenomas and inflammatory bowel disease. Clin. Epigenet. 2018, 10, 72. [CrossRef]

155. Mariani, C.J.; Vasanthakumar, A.; Madzo, J.; Yesilkanal, A.; Bhagat, T.; Yu, Y.; Bhattacharyya, S.; Wenger, R.H.; Cohn, S.L.; Nanduri, J.; et al. TET1-Mediated hydroxymethylation facilitates hypoxic gene induction in neuroblastoma. Cell Rep. 2014, 7, 1343-1352. [CrossRef]

156. Tsai, Y.P.; Chen, H.F.; Chen, S.Y.; Cheng, W.C.; Wang, H.W.; Shen, Z.J.; Song, C.; Teng, S.C.; He, C.; Wu, K.J. TET1 regulates hypoxia-induced epithelial-mesenchymal transition by acting as a co-activator. Genome Biol. 2014, 15, 513. [CrossRef]

157. Thienpont, B.; Steinbacher, J.; Zhao, H.; D'Anna, F.; Kuchnio, A.; Ploumakis, A.; Ghesquière, B.; Van Dyck, L.; Boeckx, B.; Schoonjans, L.; et al. Tumour hypoxia causes DNA hypermethylation by reducing TET activity. Nature 2016, 537, 63-68. [CrossRef] [PubMed]

158. Goldkorn, T.; Filosto, S.; Chung, S. Lung injury and lung cancer caused by cigarette smoke-induced oxidative stress: Molecular mechanisms and therapeutic opportunities involving the ceramide-generating machinery and epidermal growth factor receptor Antioxid. Redox Signal. 2014, 21, 2149-2174. [CrossRef]

159. Seiler, C.L.; Song, J.U.M.; Kotandeniya, D.; Chen, J.; Kono, T.J.Y.; Han, Q.; Colwell, M.; Auch, B.; Sarver, A.L.; Upadhyaya, P.; et al. Inhalation exposure to cigarette smoke and inflammatory agents induces epigenetic changes in the lung. Sci. Rep. 2020, 10, 11290. [CrossRef]

160. Münzel, T.; Hahad, O.; Kuntic, M.; Keaney, J.F.; Deanfield, J.E.; Daiber, A. Effects of tobacco cigarettes, e-cigarettes, and waterpipe smoking on endothelial function and clinical outcomes. Eur. Heart J. 2020, 41, 4057-4070. [CrossRef] [PubMed]

161. Federico, A.; Morgillo, F.; Tuccillo, C.; Ciardiello, F.; Loguercio, C. Chronic inflammation and oxidative stress in human carcinogenesis. Int. J. Cancer 2007, 121, 2381-2386. [CrossRef]

162. Klaunig, J.E. Oxidative Stress and Cancer. Curr. Pharm. Des. 2018, 24, 4771-4778. [CrossRef]

163. Saikolappan, S.; Kumar, B.; Shishodia, G.; Koul, S.; Koul, H.K. Reactive oxygen species and cancer: A complex interaction. Cancer Lett. 2019, 452, 132-143. [CrossRef]

164. Tommasi, S.; Besaratinia, A. DNA Hydroxymethylation at the Interface of the Environment and Nonalcoholic Fatty Liver Disease. Int. J. Environ. Res. Public Health 2019, 16, 2791. [CrossRef] [PubMed]

165. Alnajjar, K.S.; Sweasy, J.B. A new perspective on oxidation of DNA repair proteins and cancer. DNA Repair 2019, 76, 60-69. [CrossRef]

166. Tommasi, S.; Yoon, J.I.; Besaratinia, A. Secondhand Smoke Induces Liver Steatosis through Deregulation of Genes Involved in Hepatic Lipid Metabolism. Int. J. Mol. Sci. 2020, 21, 1296. [CrossRef] [PubMed]

167. Caliri, A.W.; Tommasi, S.; Besaratinia, A. Relationships among smoking, oxidative stress, inflammation, macromolecular damage, and cancer. Mutat. Res. Rev. Mutat. Res. 2021, 787, 108365. [CrossRef]

168. Cheung, E.C.; Vousden, K.H. The role of ROS in tumour development and progression. Nat. Rev. Cancer 2022, 22, 1-18. [CrossRef] [PubMed]

169. Caliri, A.W.; Caceres, A.; Tommasi, S.; Besaratinia, A. Hypomethylation of LINE-1 repeat elements and global loss of DNA hydroxymethylation in vapers and smokers. Epigenetics 2020, 15, 816-829. [CrossRef] [PubMed]

170. Ringh, M.V.; Hagemann-Jensen, M.; Needhamsen, M.; Kular, L.; Breeze, C.E.; Sjoholm, L.K.; Slavec, L.; Kullberg, S.; Wahlstrom, J.; Grunewald, J.; et al. Tobacco smoking induces changes in true DNA methylation, hydroxymethylation and gene expression in bronchoalveolar lavage cells. EBioMedicine 2019, 46, 290-304. [CrossRef] [PubMed]

171. Andersen, A.; Reimer, R.; Dawes, K.; Becker, A.; Hutchens, N.; Miller, S.; Dogan, M.; Hundley, B.; Mills, J.A.; Long, J.D.; et al. DNA methylation differentiates smoking from vaping and non-combustible tobacco use. Epigenetics 2021, 17, 178-190. [CrossRef]

172. Besaratinia, A.; Pfeifer, G.P. Second-Hand smoke and human lung cancer. Lancet Oncol. 2008, 9, 657-666. [CrossRef]

173. Vargas, A.J.; Harris, C.C. Biomarker development in the precision medicine era: Lung cancer as a case study. Nat. Rev. Cancer 2016, 16, 525-537. [CrossRef]

174. Saw, S.P.L.; Ong, B.H.; Chua, K.L.M.; Takano, A.; Tan, D.S.W. Revisiting neoadjuvant therapy in non-small-cell lung cancer. Lancet Oncol. 2021, 22, e501-e516. [CrossRef]

175. Bogart, J.A.; Waqar, S.N.; Mix, M.D. Radiation and Systemic Therapy for Limited-Stage Small-Cell Lung Cancer. J. Clin. Oncol. 2022, 40, 661-670. [CrossRef]

176. Gridelli, C.; Rossi, A.; Carbone, D.P.; Guarize, J.; Karachaliou, N.; Mok, T.; Petrella, F.; Spaggiari, L.; Rosell, R. Non-Small-Cell lung cancer. Nat. Rev. Dis. Primers 2015, 1, 15009. [CrossRef] [PubMed]

177. Wang, M.; Herbst, R.S.; Boshoff, C. Toward personalized treatment approaches for non-small-cell lung cancer. Nat. Med. 2021, 27 1345-1356. [CrossRef] [PubMed] 
178. Li, X.; Liu, Y.; Salz, T.; Hansen, K.D.; Feinberg, A. Whole-Genome analysis of the methylome and hydroxymethylome in normal and malignant lung and liver. Genome Res. 2016, 26, 1730-1741. [CrossRef]

179. Wang, Z.; Du, M.; Yuan, Q.; Guo, Y.; Hutchinson, J.N.; Su, L.; Zheng, Y.; Wang, J.; Mucci, L.A.; Lin, X.; et al. Epigenomic analysis of 5-hydroxymethylcytosine $(5 \mathrm{hmC})$ reveals novel DNA methylation markers for lung cancers. Neoplasia 2020, 22, 154-161. [CrossRef]

180. Song, C.X.; Yin, S.; Ma, L.; Wheeler, A.; Chen, Y.; Zhang, Y.; Liu, B.; Xiong, J.; Zhang, W.; Hu, J.; et al. 5-Hydroxymethylcytosine signatures in cell-free DNA provide information about tumor types and stages. Cell Res. 2017, 27, 1231-1242. [CrossRef] [PubMed]

181. Zhang, J.; Han, X.; Gao, C.; Xing, Y.; Qi, Z.; Liu, R.; Wang, Y.; Zhang, X.; Yang, Y.G.; Li, X.; et al. 5-Hydroxymethylome in Circulating Cell-free DNA as A Potential Biomarker for Non-small-cell Lung Cancer. Genom. Proteom. Bioinform. 2018, 16, 187-199. [CrossRef] [PubMed]

182. Forloni, M.; Gupta, R.; Nagarajan, A.; Sun, L.S.; Dong, Y.; Pirazzoli, V.; Toki, M.; Wurtz, A.; Melnick, M.A.; Kobayashi, S.; et al. Oncogenic EGFR Represses the TET1 DNA Demethylase to Induce Silencing of Tumor Suppressors in Cancer Cells. Cell Rep. 2016, 16, 457-471. [CrossRef]

183. Herbst, R.S.; Heymach, J.V.; Lippman, S.M. Lung cancer. N. Engl. J. Med. 2008, 359, 1367-1380. [CrossRef]

184. Huang, P.H.; Xu, A.M.; White, F.M. Oncogenic EGFR signaling networks in glioma. Sci. Signal. 2009, 2, re6. [CrossRef]

185. Foley, J.; Nickerson, N.K.; Nam, S.; Allen, K.T.; Gilmore, J.L.; Nephew, K.P.; Riese, D.J., 2nd. EGFR signaling in breast cancer: Bad to the bone. Semin. Cell Dev. Biol. 2010, 21, 951-960. [CrossRef]

186. Jordan, B.; Meeks, J.J. T1 bladder cancer: Current considerations for diagnosis and management. Nat. Rev. Urol. 2019, 16, 23-34. [CrossRef] [PubMed]

187. Lenis, A.T.; Lec, P.M.; Chamie, K.; Mshs, M.D. Bladder Cancer: A Review. JAMA 2020, 324, 1980-1991. [CrossRef]

188. Tran, L.; Xiao, J.F.; Agarwal, N.; Duex, J.E.; Theodorescu, D. Advances in bladder cancer biology and therapy. Nat. Rev. Cancer 2021, 21, 104-121. [CrossRef]

189. Lobo, N.; Mount, C.; Omar, K.; Nair, R.; Thurairaja, R.; Khan, M.S. Landmarks in the treatment of muscle-invasive bladder cancer. Nat. Rev. Urol. 2017, 14, 565-574. [CrossRef] [PubMed]

190. Schubert, T.; Rausch, S.; Fahmy, O.; Gakis, G.; Stenzl, A. Optical improvements in the diagnosis of bladder cancer: Implications for clinical practice. Ther. Adv. Urol. 2017, 9, 251-260. [CrossRef] [PubMed]

191. Besaratinia, A.; Tommasi, S. Genotoxicity of tobacco smoke-derived aromatic amines and bladder cancer: Current state of knowledge and future research directions. FASEB J. 2013, 27, 2090-2100. [CrossRef]

192. Besaratinia, A.; Cockburn, M.; Tommasi, S. Alterations of DNA methylome in human bladder cancer. Epigenetics 2013, 8 , 1013-1022. [CrossRef]

193. Alifrangis, C.; McGovern, U.; Freeman, A.; Powles, T.; Linch, M. Molecular and histopathology directed therapy for advanced bladder cancer. Nat. Rev. Urol. 2019, 16, 465-483. [CrossRef]

194. Boffetta, P. Tobacco smoking and risk of bladder cancer. Scand. J. Urol. Nephrol. 2008, 42, 45-54. [CrossRef]

195. Peng, D.; Ge, G.; Gong, Y.; Zhan, Y.; He, S.; Guan, B.; Li, Y.; Xu, Z.; Hao, H.; He, Z.; et al. Vitamin C increases 5hydroxymethylcytosine level and inhibits the growth of bladder cancer. Clin. Epigenet. 2018, 10, 94. [CrossRef]

196. Munari, E.; Chaux, A.; Vaghasia, A.M.; Taheri, D.; Karram, S.; Bezerra, S.M.; Gonzalez Roibon, N.; Nelson, W.G.; Yegnasubramanian, S.; Netto, G.J.; et al. Global 5-Hydroxymethylcytosine Levels Are Profoundly Reduced in Multiple Genitourinary Malignancies. PLoS ONE 2016, 11, e0146302. [CrossRef] [PubMed]

197. Zhu, J.; Huang, G.; Hua, X.; Li, Y.; Yan, H.; Che, X.; Tian, Z.; Liufu, H.; Huang, C.; Li, J.; et al. CD44s is a crucial ATG7 downstream regulator for stem-like property, invasion, and lung metastasis of human bladder cancer (BC) cells. Oncogene 2019, 38, 3301-3315. [CrossRef] [PubMed]

198. Hu, B.; Shi, G.; Li, Q.; Li, W.; Zhou, H. Long noncoding RNA XIST participates in bladder cancer by downregulating p53 via binding to TET1. J. Cell Biochem. 2019, 120, 6330-6338. [CrossRef] [PubMed]

199. Meeks, J.J.; Al-Ahmadie, H.; Faltas, B.M.; Taylor, J.A., 3rd; Flaig, T.W.; DeGraff, D.J.; Christensen, E.; Woolbright, B.L.; McConkey, D.J.; Dyrskjøt, L. Genomic heterogeneity in bladder cancer: Challenges and possible solutions to improve outcomes. Nat. Rev. Urol. 2020, 17, 259-270. [CrossRef]

200. Van der Stok, E.P.; Spaander, M.C.W.; Grünhagen, D.J.; Verhoef, C.; Kuipers, E.J. Surveillance after curative treatment for colorectal cancer. Nat. Rev. Clin. Oncol. 2017, 14, 297-315. [CrossRef] [PubMed]

201. Smith, R.A.; Fedewa, S.; Siegel, R. Early colorectal cancer detection-Current and evolving challenges in evidence, guidelines, policy, and practices. Adv. Cancer Res. 2021, 151, 69-107. [CrossRef]

202. Akimoto, N.; Ugai, T.; Zhong, R.; Hamada, T.; Fujiyoshi, K.; Giannakis, M.; Wu, K.; Cao, Y.; Ng, K.; Ogino, S. Rising incidence of early-onset colorectal cancer-A call to action. Nat. Rev. Clin. Oncol. 2021, 18, 230-243. [CrossRef]

203. Srivastava, S.; Koay, E.J.; Borowsky, A.D.; De Marzo, A.M.; Ghosh, S.; Wagner, P.D.; Kramer, B.S. Cancer overdiagnosis: A biological challenge and clinical dilemma. Nat. Rev. Cancer 2019, 19, 349-358. [CrossRef]

204. Clarke, W.T.; Feuerstein, J.D. Colorectal cancer surveillance in inflammatory bowel disease: Practice guidelines and recent developments. World J. Gastroenterol. 2019, 25, 4148-4157. [CrossRef]

205. Kolb, J.M.; Molmenti, C.L.; Patel, S.G.; Lieberman, D.A.; Ahnen, D.J. Increased Risk of Colorectal Cancer Tied to Advanced Colorectal Polyps: An Untapped Opportunity to Screen First-Degree Relatives and Decrease Cancer Burden. Am. J. Gastroenterol. 2020, 115, 980-988. [CrossRef] 
206. Zhou, X.; Zhuang, Z.; Wang, W.; He, L.; Wu, H.; Cao, Y.; Pan, F.; Zhao, J.; Hu, Z.; Sekhar, C.; et al. OGG1 is essential in oxidative stress induced DNA demethylation. Cell Signal. 2016, 28, 1163-1171. [CrossRef] [PubMed]

207. Chapman, C.G.; Mariani, C.J.; Wu, F.; Meckel, K.; Butun, F.; Chuang, A.; Madzo, J.; Bissonnette, M.B.; Kwon, J.H.; Godley, L.A. TET-catalyzed 5-hydroxymethylcytosine regulates gene expression in differentiating colonocytes and colon cancer. Sci. Rep. 2015, 5, 17568. [CrossRef]

208. Sheaffer, K.L.; Kim, R.; Aoki, R.; Elliott, E.N.; Schug, J.; Burger, L.; Schübeler, D.; Kaestner, K.H. DNA methylation is required for the control of stem cell differentiation in the small intestine. Genes Dev. 2014, 28, 652-664. [CrossRef] [PubMed]

209. Li, W.; Zhang, X.; Lu, X.; You, L.; Song, Y.; Luo, Z.; Zhang, J.; Nie, J.; Zheng, W.; Xu, D.; et al. 5-Hydroxymethylcytosine signatures in circulating cell-free DNA as diagnostic biomarkers for human cancers. Cell Res. 2017, 27, 1243-1257. [CrossRef] [PubMed]

210. Rawłuszko-Wieczorek, A.A.; Siera, A.; Horbacka, K.; Horst, N.; Krokowicz, P.; Jagodziński, P.P. Clinical significance of DNA methylation mRNA levels of TET family members in colorectal cancer. J. Cancer Res. Clin. Oncol. 2015, 141, 1379-1392. [CrossRef]

211. Neri, F.; Dettori, D.; Incarnato, D.; Krepelova, A.; Rapelli, S.; Maldotti, M.; Parlato, C.; Paliogiannis, P.; Oliviero, S. TET1 is a tumour suppressor that inhibits colon cancer growth by derepressing inhibitors of the WNT pathway. Oncogene 2015, 34, 4168-4176. [CrossRef]

212. Tommasi, S.; Caliri, A.W.; Caceres, A.; Moreno, D.E.; Li, M.; Chen, Y.; Siegmund, K.D.; Besaratinia, A. Deregulation of Biologically Significant Genes and Associated Molecular Pathways in the Oral Epithelium of Electronic Cigarette Users. Int. J. Mol. Sci. 2019, 20, 738. [CrossRef]

213. Tommasi, S.; Pabustan, N.; Li, M.; Chen, Y.; Siegmund, K.D.; Besaratinia, A. A novel role for vaping in mitochondrial gene dysregulation and inflammation fundamental to disease development. Sci. Rep. 2021, 11, 22773. [CrossRef]

214. Duffy, M.J.; Crown, J. Use of Circulating Tumour DNA (ctDNA) for Measurement of Therapy Predictive Biomarkers in Patients with Cancer. J. Pers. Med. 2022, 12, 99. [CrossRef]

215. Wan, J.C.M.; Massie, C.; Garcia-Corbacho, J.; Mouliere, F.; Brenton, J.D.; Caldas, C.; Pacey, S.; Baird, R.; Rosenfeld, N. Liquid biopsies come of age: Towards implementation of circulating tumour DNA. Nat. Rev. Cancer 2017, 17, 223-238. [CrossRef]

216. Yu, F.; Li, K.; Li, S.; Liu, J.; Zhang, Y.; Zhou, M.; Zhao, H.; Chen, H.; Wu, N.; Liu, Z.; et al. CFEA: A cell-free epigenome atlas in human diseases. Nucleic Acids Res. 2020, 48, D40-D44. [CrossRef] [PubMed]

217. Besaratinia, A.; Tommasi, S. Vaping epidemic: Challenges and opportunities. Cancer Causes Control 2020, 31, 663-667. [CrossRef] [PubMed]

218. Gordon, T.; Karey, E.; Rebuli, M.E.; Escobar, Y.; Jaspers, I.; Chi Chen, L. E-Cigarette Toxicology. Annu. Rev. Pharmacol. Toxicol. 2021, 62, 301-322. [CrossRef] [PubMed]

219. Besaratinia, A. COVID-19: A pandemic converged with global tobacco epidemic and widespread vaping-state of the evidence. Carcinogenesis 2021, 42, 1009-1022. [CrossRef] [PubMed]

220. Besaratinia, A.; Tommasi, S. The consequential impact of JUUL on youth vaping and the landscape of tobacco products: The state of play in the COVID-19 era. Prev. Med. Rep. 2021, 22, 101374. [CrossRef] [PubMed]

221. Wills, T.A.; Soneji, S.S.; Choi, K.; Jaspers, I.; Tam, E.K. E-Cigarette use and respiratory disorders: An integrative review of converging evidence from epidemiological and laboratory studies. Eur. Respir. J. 2021, 57, 1901815. [CrossRef]

222. Besaratinia, A. From Tobacco Cigarettes to Electronic Cigarettes: The Two Sides of a Nicotine Coin. Front. Oral Health 2021, 2 , 790634. [CrossRef]

223. Balfour, D.J.K.; Benowitz, N.L.; Colby, S.M.; Hatsukami, D.K.; Lando, H.A.; Leischow, S.J.; Lerman, C.; Mermelstein, R.J.; Niaura, R.; Perkins, K.A.; et al. Balancing Consideration of the Risks and Benefits of E-Cigarettes. Am. J. Public Health 2021, 111, 1661-1672. [CrossRef] 